\title{
Long-term outcomes of mechanical versus biological aortic valve prosthesis: Systematic review and meta-analysis
}

\author{
Rocio Diaz, MD, PhD, ${ }^{\mathrm{a}, \mathrm{b}}$ Daniel Hernandez-Vaquero, $\mathrm{MD}, \mathrm{PhD},{ }^{\mathrm{a}, \mathrm{b}}$ Ruben Alvarez-Cabo, MD, ${ }^{\mathrm{a}}$ \\ Pablo Avanzas, MD, PhD, ${ }^{\text {a,b }}$ Jacobo Silva, MD, PhD, ${ }^{\mathrm{a}, \mathrm{c}}$ Cesar Moris, MD, PhD, ${ }^{\mathrm{a}, \mathrm{b}, \mathrm{c}}$ and \\ Isaac Pascual, $\mathrm{MD}, \mathrm{PhD}^{\mathrm{a}, \mathrm{b}}$
}

\section{ABSTRACT}

Background: In recent years, the use of surgically implanted biological aortic valves has been favored over mechanical prosthesis in patients between 50 and 70 years of age. However, outcomes on long-term survival are contradictory. The objective of this study was to determine if patients with mechanical valves have worse long-term survival than patients with biological prostheses.

Methods: We systematically searched published studies that: (1) were propensity score-matched or randomized controlled trials; (2) provided survival data with a minimum follow-up of 5 years; and (3) included patients older than 50 and younger than 70 years of age. Review articles, case reports, and editorials were excluded. We conducted a meta-analysis on the basis of 2 types of analysis. A reconstruction of the database of each study to simulate a patient-level meta-analysis was performed. Log rank test of Kaplan-Meier curves was recalculated. Hazard ratio (HR) was calculated using a univariate Cox regression. In addition, we calculated a pooled HR using the fixed-effect inverse variance method.

Results: Four propensity score-matched studies and 1 randomized controlled trial met the inclusion criteria. Data of 4686 patients were analyzed. Survival rates for mechanical versus biological valves at 10 and 15 years of follow-up were: $76.78 \%$ (95\% confidence interval [CI], 74.72\%-78.69\%) versus $74.09 \%$ (95\% CI, 71.96\%-76.08\%), and 61.58\% (95\% CI, 58.29\%-64.69\%) versus $58.04 \%(95 \%$ CI, 54.57\%-61.35\%). Log rank test was statistically significant $(P=.012)$ and the pooled HR was $0.86(95 \% \mathrm{CI}, 0.76-0.97 ; P=.01)$.

Conclusions: Compared with biological aortic valves, mechanical valves are associated with a long-term survival benefit for patients between 50 and 70 years. (J Thorac Cardiovasc Surg 2019;158:706-14)

From the ${ }^{\mathrm{a}}$ Heart Area, Hospital Universitario Central de Asturias, Oviedo, Spain; ${ }^{\mathrm{b}} \mathrm{In}-$ stituto de Investigación Sanitaria del Principado de Asturias, Oviedo, Spain; and ${ }^{\mathrm{c}}$ Department of Medicine, University of Oviedo, Oviedo, Spain.

Received for publication July 24, 2018; revisions received Oct 17, 2018; accepted for publication Oct 26, 2018; available ahead of print Dec 20, 2018.

Address for reprints: Daniel Hernandez-Vaquero, MD, PhD, Heart Area, Hospital Universitario Central de Asturias, Avenida de Roma, 33011, Oviedo, Spain (E-mail: dhvaquero@gmail.com).

0022-5223/\$36.00

Copyright (c) 2018 by The American Association for Thoracic Surgery

https://doi.org/10.1016/j.jtcvs.2018.10.146

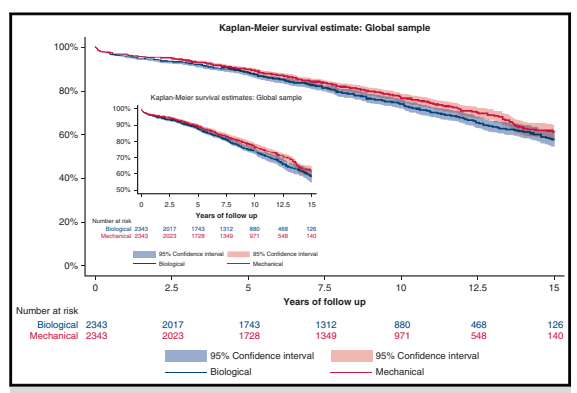

Kaplan-Meier survival curves of the mechanical versus biological arm. The mechanical group has better long-term survival.

\section{Central Message}

Compared with biological aortic valves, mechanical valves are associated with a longterm survival benefit for patients between 50 and 70 years of age.

\section{Perspective}

In recent years, the use of biological valves has been favored over mechanical ones. Nowadays, approximately $80 \%$ of implanted prostheses are biological valves and this trend is likely to keep increasing. However, mechanical valves are associated with a long-term survival benefit for patients between 50 and 70 years of age. Therefore, the choice of a bioprosthesis in patients of this age range requires a rigorous and comprehensive of their possible life expectancy, therapeutic adherence, and risk profile of bleeding or thromboembolism.

See Commentaries on pages 715 and 716.

Aortic valve replacement is the standard procedure to treat severe aortic stenosis. Two types of prosthesis can be surgically implanted: mechanical and bioprosthetic valves.

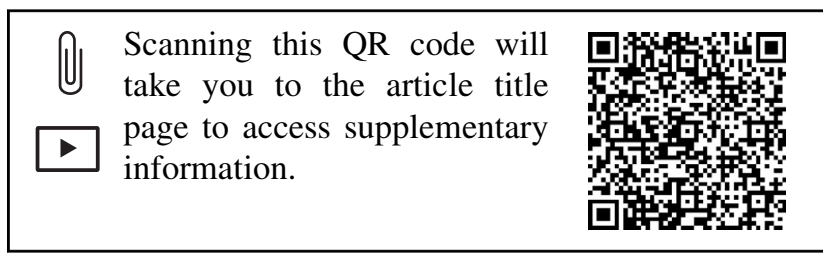



Abbreviations and Acronyms
$\mathrm{CI}=$ confidence interval
$\mathrm{HR}=$ hazard ratio
$\mathrm{IRR}=$ incidence rate ratio
$\mathrm{PS}=$ propensity score
$\mathrm{PSM}=$ propensity score-matched
$\mathrm{RCT}=$ randomized controlled trial

There is consensus that patients with biological aortic prostheses require reoperation more frequently than patients with mechanical prostheses because of the limited durability of the bioprosthetic valves. ${ }^{1}$ In contrast, patients with mechanical prostheses have risks related to anticoagulation therapy ${ }^{1}$ and this is often the reason to refrain from choosing them. In terms of long-term survival, reported results are more contradictory.

In recent years, the use of biological aortic valves has been favored over mechanical ones. Nowadays, approximately $80 \%$ of implanted prostheses are biological valves and this trend is likely to keep increasing. ${ }^{1}$ In 2017 a consensus document by the American College of Cardiology and American Heart Association indicated a lowered the age limit from which the use of biological prosthesis is reasonable from 60 to 50 years of age. ${ }^{2}$ These recommendations are supported by recent observational studies that have not shown differences in survival in patients between 50 and 70 years of age with mechanical versus biological aortic valves. ${ }^{3,4}$ However, other researchers have reported better long-term survival for patients with mechanical prostheses who are in this age range. . $^{5}$

Although the best scientific evidence is provided by randomized controlled trials (RCTs), in surgery, RCTs present several methodological and practical challenges. ${ }^{7}$ Propensity score (PS) methods are statistical techniques used for dealing with the intrinsic biases of observational studies. PS calculations achieve more robust, more precise, and less biased estimations than usual regression analysis in the presence of few events. ${ }^{8}$ Moreover, PS matching is more robust to mis-specification of the PS model than other PS methods, eliminates a greater proportion of systematic differences, ${ }^{8,9}$ and permits, for a pooled analysis, the relatively unbiased calculation of time to event outcomes and hazard ratio (HR) values from Kaplan-Meier survival curves of the matched population. To provide the best available evidence, we present a meta-analysis of RCT and PS-matched (PSM) observational studies published until March 2018 that compared long-term survival of patients between 50 and 70 years of age with surgically implanted mechanical versus biological aortic prosthesis (Videos 1 and 2).

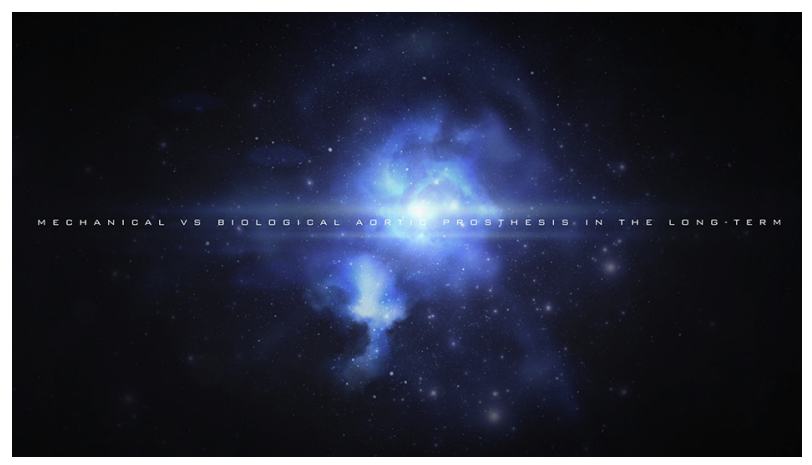

VIDEO 1. Abstract of the meta-analysis (turn the sound on). Video available at: https://www.jtcvs.org/article/S0022-5223(18)32969-6/fulltext.

\section{METHODS}

The study was conducted following a prespecified protocol; the summary is registered in PROSPERO (registration number: CRD42017076611) before the beginning of the meta-analysis. This work was performed on the basis of the Preferred Reporting Items for Systematic Reviews and Meta-Analyses guidelines. ${ }^{10}$ More information is shown in Appendix E1, Online Data Supplement 1, and Online Data Supplement 2.

\section{Search Strategy and Election of the Studies}

In March 2018, Medline through PubMed, Embase, Web of Science, and The Cochrane Central Register of Controlled Trials were used to identify adequate articles. The search was not based on key words only, but the free search option was used. The full Medline strategy via PubMed is described in Appendix E1 and was applied to all databases. Studies had to fulfill the following inclusion criteria: (1) PSM studies or RCTs comparing surgically implanted mechanical versus biological prosthesis; (2) provides survival data with a minimum follow-up of 5 years; and (3) patients older than 50 and younger than 70 years of age. Review articles, case reports, editorials and non-English reports were excluded. More information on the election of the studies and data extraction is shown in Appendix E1.

The primary end-point was long term survival. Secondary end points included rate of reoperation, major bleeding, and stroke.

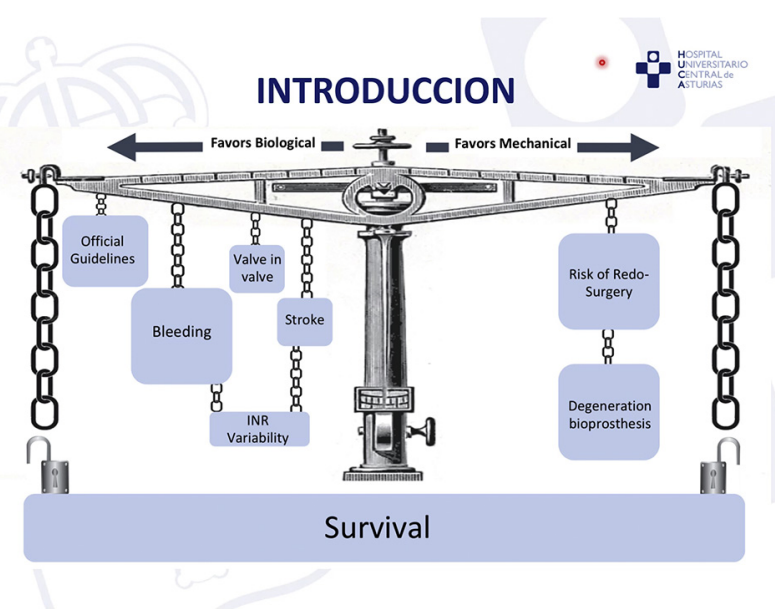

VIDEO 2. Summary of this meta-analysis (turn the sound on). Video available at: https://www.jtcvs.org/article/S0022-5223(18)32969-6/fulltext. 


\section{Study Quality}

To provide quality information of the RCT and PSM articles, the Revised Tool To Assess Risk Of Bias In Randomized Trials version 2.0 ${ }^{11}$ and the Risk of bias In Non-randomized Studies Of Interventions I tool were respectively used. ${ }^{12}$ The Revised Tool To Assess Risk Of Bias In Randomized Trials version 2.0 and the ROBINS I assess the potential risk of bias in 5 and 7 domains, respectively. The quality of the studies was independently evaluated by two reviewers (R.D. and R.A.-C.).

\section{Statistical Analysis}

Continuous and categorical variables were respectively reported as mean (standard deviation) and $\mathrm{n}$ (percentage). For survival analysis we used 2 statistical pooling methods. We first performed a simulation of a patient-level meta-analysis. To do this, we reconstructed the database of each article using the method of Wei and colleagues, ${ }^{13}$ and merged all data into 1 database. In this global database, life tables, survival curve, incidence function, and HR were calculated. The log rank test stratified according to study was used to assess differences between both groups. A stratified Cox proportional hazard model was used to calculate the HR of mechanical versus biological prosthesis. Hazards proportionality was assessed using the test on the basis of Schoenfeld residuals and a likelihood ratio test was performed to assess the homogeneity of data. We used the fixed effect inverse variance method as a complementary analysis with aggregated data. The association measure was HR (risk of death) of mechanical versus biological prosthesis. The HR was calculated reconstructing the original database ${ }^{13}$ and performing a univariate Cox model. We tested this method by graphing the new survival curves and comparing them with the original survival curves though visual assessment and, when the original publication provided HRs, comparing the new calculated HR with the original HR. More information is available in Appendix E1.

We preferred the fixed effect to the random effect model because of its ability to easily observe heterogeneity between studies. No heterogeneity was considered to exist when the $P$ value of the Q test was $>0.10$ or $I^{2}$ $<50 \%$. If there was heterogeneity, the pooled analysis was not considered valid. Absence of heterogeneity was confirmed according to Galbraith plot and visual inspection of the forest plot. Sensitivity analysis was performed calculating the influence of deleting 1 article. Although subgroup analysis was prespecified (50-60 and 60-70 years of age), it was not performed because of the small number of articles included in the pooled analysis. A cumulative meta-analysis according to date of publication was also constructed. For publication bias evaluation, we used Egger test with Harbord modification, which has been shown to be highly sensitive, ${ }^{14}$ and Peters test, which has been shown to be highly specific regardless of heterogeneity. ${ }^{15}$ Funnel plots were created.

Databases were not reconstructed for secondary objectives because they need to be calculated using the cumulative incidence function in the presence of competing events, usually death. ${ }^{16}$ Therefore, the previous method $^{13}$ is not valid. To compute a pooled associate measure we calculated the incidence rate ratio (IRR) from each individual work and the fixed effect inverse variance method was used. We used the figures provided in the article. When theses figures were not provided, data were extracted from curves using GetData Graph Digitizer (available at: http://getdata-graph-digitizer.com/). If the Q test was $\leq 0.10$ or $I^{2} \geq 50 \%$, the pooled analysis was not considered valid. Publication bias was
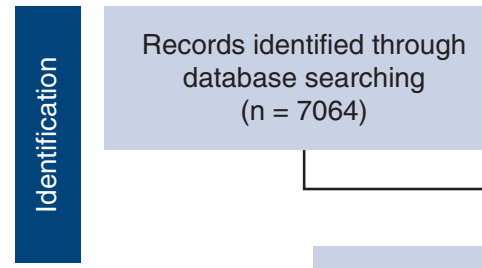

Additional records identified through other sources $(n=7064)$

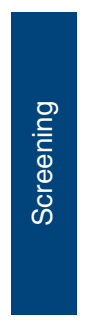

Records after duplicates $(n=0)$

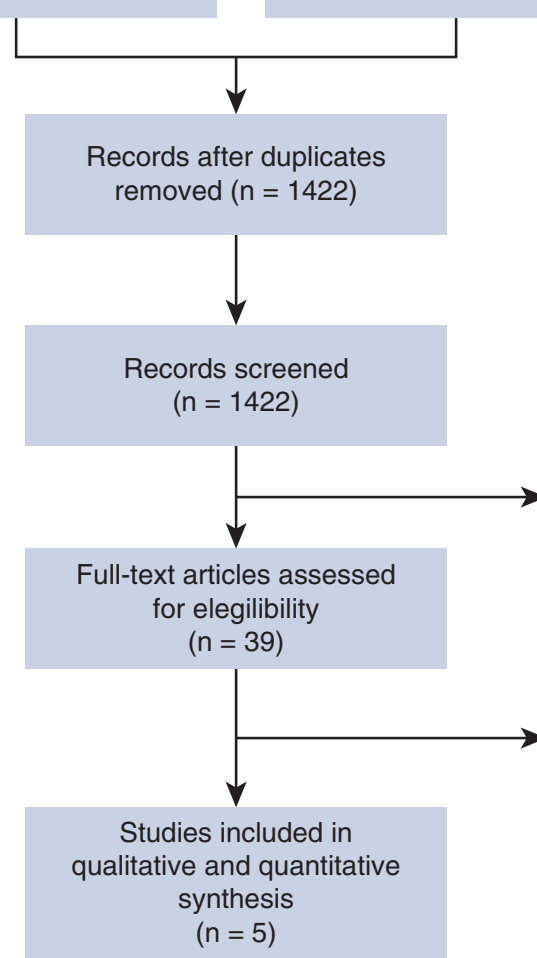

Records excluded $(n=1383)$

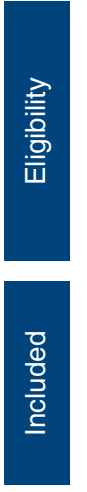

Full-text articles excluded

Reasons: $(n=34)$

- Age out of range

$(n=25)$

- Not Propensity Score

Matched $(n=9)$

FIGURE 1. Election of the studies on the basis of the Preferred Reporting Items for Systematic Reviews and Meta-Analyses Flow Diagram. We evaluated 1422 titles and abstracts; 1383 were excluded and 39 articles required full-text evaluation; 34 articles were excluded and only 5 met all of the inclusion criteria. 
TABLE 1. Overview of the studies included in the meta-analysis

\begin{tabular}{|c|c|c|c|c|c|c|c|c|}
\hline Reference & Country & $\begin{array}{l}\text { Main authors' } \\
\text { institution(s) }\end{array}$ & Study period & $\begin{array}{l}\text { Study } \\
\text { design }\end{array}$ & Mechanical valve & Biological valve & $\begin{array}{l}\text { Outcomes } \\
\text { reported }\end{array}$ & $\begin{array}{c}\text { Risk of } \\
\text { bias }\end{array}$ \\
\hline $\begin{array}{l}\text { Stassano and } \\
\text { colleagues }^{17}\end{array}$ & Italy & $\begin{array}{l}\text { University Federico II } \\
\text { Istituto Clinico Pineta } \\
\text { Grande }\end{array}$ & 1995 to 2003 & RCT & $\begin{array}{l}\text { St Jude Medical } \\
\text { (St. Jude Medical, } \\
\text { Inc., St. Paul, } \\
\text { Minn.) } \\
\text { CarboMedics } \\
\text { (Sorin Group, } \\
\text { Milano, Italy) }\end{array}$ & $\begin{array}{l}\text { Carpentier-Edwards } \\
\text { SAV (Edwards } \\
\text { Lifesciences, } \\
\text { Irvine, Calif.) } \\
\text { Carpentier-Edwards } \\
\text { Pericardial (Edwards } \\
\text { Lifesciences, Irvine, } \\
\text { Calif.) }\end{array}$ & $\begin{array}{l}\text { Late survival } \\
\text { Reoperation } \\
\text { Stroke } \\
\text { Bleeding }\end{array}$ & Low \\
\hline $\begin{array}{l}\text { Roumieh and } \\
\text { colleagues }^{18}\end{array}$ & Germany & $\begin{array}{l}\text { Hannover Medical } \\
\text { School }\end{array}$ & 1997 to 2008 & PSM & St Jude Medical & $\begin{array}{l}\text { Medtronic Mosaic } \\
\text { (Medtronic Inc, } \\
\text { Minneapolis, Minn.) } \\
\text { Sorin Mitroflow } \\
\text { Carpentier-Edwards } \\
\text { Perimount (Edwards } \\
\text { Lifesciences, Irvine, } \\
\text { Calif.) } \\
\text { St Jude Medical Toronto }\end{array}$ & $\begin{array}{l}\text { Late Survival } \\
\text { Reoperation } \\
\text { Stroke } \\
\text { Bleeding }\end{array}$ & Low \\
\hline $\begin{array}{l}\text { Chiang and } \\
\text { colleagues }^{3}\end{array}$ & USA & $\begin{array}{l}\text { Mount Sinai Medical } \\
\text { Center }\end{array}$ & 1997 to 2004 & PSM & Not reported & Not reported & $\begin{array}{l}\text { Late Survival } \\
\text { Reoperation } \\
\text { Stroke } \\
\text { Bleeding }\end{array}$ & Low \\
\hline $\begin{array}{l}\text { Glaser and } \\
\text { colleagues }^{5}\end{array}$ & Sweden & $\begin{array}{l}\text { Karolinska University } \\
\text { Hospital }\end{array}$ & 1997 to 2013 & PSM & Not reported & Not reported & $\begin{array}{l}\text { Late Survival } \\
\text { Reoperation } \\
\text { Stroke } \\
\text { Bleeding }\end{array}$ & Low \\
\hline $\begin{array}{l}\text { Sakamoto and } \\
\text { colleagues }^{19}\end{array}$ & Japan & $\begin{array}{l}\text { Jikei University School } \\
\text { of Medicine }\end{array}$ & 1995 to 2014 & PSM & $\begin{array}{l}\text { St Jude Medical } \\
\text { Standard } \\
\text { St Jude Medical } \\
\text { Regent } \\
\text { ATS (Medtronic } \\
\text { Inc, Minneapolis, } \\
\text { Minn.) } \\
\text { CarboMedics }\end{array}$ & $\begin{array}{l}\text { Carpentier-Edwards } \\
\text { Perimount } \\
\text { Carpentier-Edwards } \\
\text { Magna (Edwards } \\
\text { Lifesciences, Irvine, } \\
\text { Calif.) } \\
\text { Carpentier-Edwards } \\
\text { Magna Ease (Edwards } \\
\text { Lifesciences, Irvine, } \\
\text { Calif.) } \\
\text { Medtronic Mosaic } \\
\text { Medtronic Ultra } \\
\text { (Medtronic Inc, } \\
\text { Minneapolis, Minn.) } \\
\text { St Jude Medical Trifecta } \\
\text { St Jude Medical Epic }\end{array}$ & $\begin{array}{l}\text { Late survival } \\
\text { Reoperation }\end{array}$ & Serious \\
\hline
\end{tabular}

RCT, Randomized controlled trial; PSM, propensity score-matched; USA, United States of America.

evaluated as aforementioned. All analyses were performed using STATA IC 15.1 (StataCorp, College Station, Tex).

\section{RESULTS}

\section{Selected Studies}

The Preferred Reporting Items for Systematic Reviews and Meta-Analyses flow diagram is shown in Figure 1. We evaluated 1422 titles and abstracts; 1383 were excluded and 39 articles required article evaluation. Thirty-four articles were excluded and only 5 met all of the inclusion criteria and were included in the qualitative and quantitative pooled analysis. One of them was a $\mathrm{RCT}^{17}$ and 4 were PSM. ${ }^{3,5,18,19}$ Table 1 shows an overview of these 5 articles with their risk of bias. The total number of patients analyzed was 4686 and 3003 patients were men. Patient characteristics of each study are shown in Table E1.

\section{Late Survival}

All studies provided data with a follow-up over 10 years. Table 2 shows mean and median follow-up. Three 
TABLE 2. Hazard ratio or relative risk of death of mechanical versus biological prosthesis during the follow-up

\begin{tabular}{|c|c|c|c|c|c|c|}
\hline \multirow[b]{2}{*}{ Reference } & \multicolumn{3}{|c|}{ Original work } & \multicolumn{3}{|c|}{ Reconstructed database } \\
\hline & HR $(95 \%$ CI $)$ & $\begin{array}{l}\text { Mean follow-up, } \\
\text { years }\end{array}$ & $\begin{array}{c}\text { Median } \\
\text { follow-up, years }\end{array}$ & $\begin{array}{c}\text { HR } \\
(95 \% \mathrm{CI})\end{array}$ & $\begin{array}{l}\text { Mean follow-up, } \\
\text { years }\end{array}$ & $\begin{array}{c}\text { Median follow-up, } \\
\text { years }\end{array}$ \\
\hline Stassano and colleagues ${ }^{17}$ & $0.73(0.45-1.19)$ & 8.8 & & $0.79(0.52-1.21)$ & 8.7 & 8.6 \\
\hline Chiang and colleagues ${ }^{3}$ & $0.97(0.83-1.14)$ & & 10.8 & $0.96(0.82-1.1)$ & 9.8 & 10.9 \\
\hline Roumieh and colleagues ${ }^{18}$ & & 9.8 & & $0.88(0.45-1.72)$ & 9.8 & 10 \\
\hline Glaser and colleagues $^{5}$ & $0.75(0.61-0.93)$ & 6.6 & & $0.75(0.61-0.92)$ & 6.6 & 6.4 \\
\hline Sakamoto and colleagues ${ }^{19}$ & & & & $0.73(0.12-4.39)$ & 8.8 & 7.9 \\
\hline
\end{tabular}

Mean and median follow-up of the original works and the reconstructed databases are shown. $H R$, Hazard ratio; $C I$, confidence interval.

studies $^{3,5,17}$ provided HR values for long-term survival. Roumieh and colleagues ${ }^{18}$ and Sakamoto and colleagues ${ }^{19}$ did not provide these measures. Table 2 shows HRs reported in the original works and HRs calculated using the reconstructed databases. In works that reported HRs, the new calculated HR was consistent. All reconstructed survival curves are shown in Figures E1 through E5.

All reconstructed databases were pooled into 1 global database. Kaplan-Meier survival curve of this global sample is shown Figure 2. The log rank test was statistically significant favoring the mechanical group $(P=.012)$. Survival rates for mechanical versus biological valves at 5 , 10 , and 15 years of follow-up were: $89.51 \% \quad(95 \%$ confidence interval [CI], 88.13\%-90.73\%) versus $88.10 \%$ $(95 \% \quad \mathrm{CI}, \quad 86.65 \%-89.39 \%), \quad 76.78 \% \quad(95 \% \quad \mathrm{CI}$, $74.72 \%-78.69 \%)$ versus $74.09 \% \quad(95 \%$ CI, $71.96 \%$ $76.08 \%)$ and $61.58 \%(95 \%$ CI, $58.29 \%-64.69 \%)$ versus $58.04 \%$ (95\% CI, 54.57\%-61.35\%). This means a number needed to treat of 28.25 patients at 15 years of follow-up. Risk of death represented as HR was 0.86 (95\% CI, 0.76$0.97 ; P=.01)$. A likelihood ratio test showed no heterogeneity $(P=.43)$. A smoothed hazard function according to type of prosthesis is shown in Figure E6. Pooled analysis on the basis of aggregated data was consistent with these findings (Appendix E1). Cumulative meta-analysis ordered according to date of publication is shown in Figure 3.

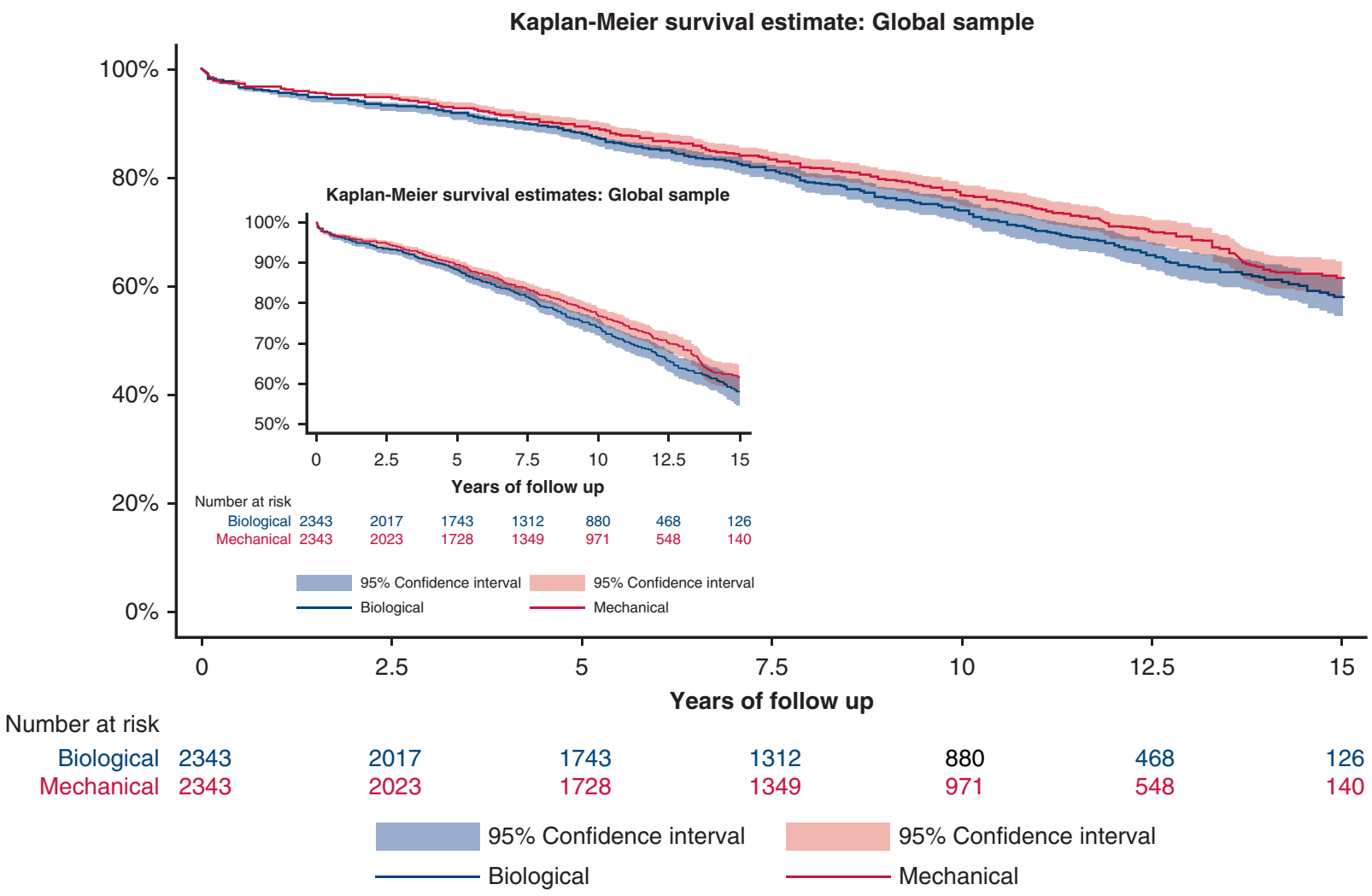

FIGURE 2. All databases were pooled into 1 global database. Kaplan-Meier survival curves of the global sample are shown. The mechanical group has better long-term survival. Curves seem to diverge from the fifth year. 


\section{Cumulative Plot}

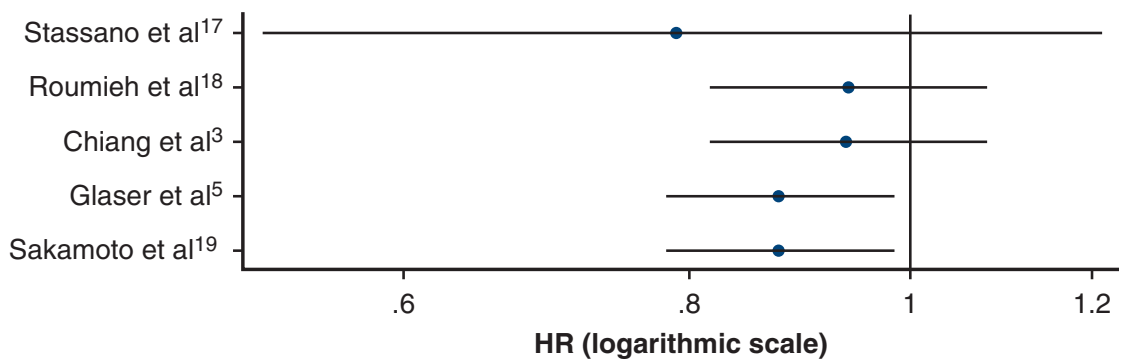

FIGURE 3. Cumulative meta-analysis according to date of publication. This graph evaluates the evolution of scientific knowledge as new works arise. Better survival in the mechanical group since the publication of Glaser and colleagues. ${ }^{5} H R$, Hazard ratio.

\section{Secondary Objectives}

In all works, reoperation rates were lower in the mechanical group. Data from Sakamoto and colleagues ${ }^{19}$ could not be included in the meta-analysis because of an incidence rate of 0 in the mechanical group. IRR was 0.46 (95\% CI, 0.35-0.60; $P<.001)$. There was no heterogeneity. The Q test had a $P=.43 ; I^{2}=.0 \%$. A Galbraith plot is shown in Figure E11. A forest plot is shown in Figure 4. There was no publication bias. The Harbord test had a $P=.14$ and Peter test had a $P=.52$. Funnel and Harbord plots are shown in Figures E12 and E13.

All articles but Sakamoto and colleagues ${ }^{19}$ provided stroke rates. Stroke risk was similar between both groups $\mathrm{IRR}=1.00(95 \% \mathrm{CI}, 0.79-1,28 ; P=1.00)$. There was no heterogeneity. The $\mathrm{Q}$ test had a $P$ value $=.28$; $I^{2}=22.2 \%$. A forest plot is shown in Figure 5. There was no publication bias. A Harbord test had a $P=.81$ and Peter test had a $P=.63$. Galbraith, funnel, and Harbord plots are shown in Figures E14 through E16.

All articles but Sakamoto and colleagues ${ }^{19}$ provided data on major bleeding. Major bleeding was higher in the mechanical group: IRR $=1.84(95 \%$ CI, 1.47-2.3; $P<.001)$. No heterogeneity was found. The $\mathrm{Q}$ test had a $P$ value $=.94 ; I^{2}=0 \%$. A forest plot is shown in
Figure 6. There was no publication bias; Harbord test showed $P=.98$ and Peter test $P=.83$. Galbraith, funnel, and Harbord plots are shown in Figures E17 through E19.

\section{DISCUSSION}

Using RCT and PSM samples, this meta-analysis provides strong evidence supporting that compared with biological aortic prostheses, mechanical valves are associated with a long-term survival benefit for patients between 50 and 70 years. The differences in survival are small, become evident during the first years and slightly increase as time goes by. After the results of the cumulative meta-analysis, these findings could have been known since 2015 and contradict the last recommendations of the American Heart Association and American College of Cardiology. ${ }^{2}$

Zhao and colleagues ${ }^{20}$ published the only meta-analysis on this topic in this age range in 2016. Despite performing the random effect inverse variance method, which can hide heterogeneity, their pooled analysis, on the basis of aggregate data, showed high levels of inconsistency $\left(P=.04, I^{2}=58 \%\right)$. However, they considered their pooled analysis valid and concluded that long-term survival was similar between patients with mechanical and biological

\begin{tabular}{|c|c|c|c|c|c|}
\hline Reference & $\begin{array}{l}\text { Study } \\
\text { design }\end{array}$ & Favors mechanical & $\underset{\text { Favors biological }}{\longrightarrow}$ & ES $(95 \% \mathrm{Cl})$ & $\begin{array}{c}\% \\
\text { Weight }\end{array}$ \\
\hline Stassano et al ${ }^{17}$ & $\mathrm{RCT}$ & $\longrightarrow$ & & $0.27(0.12-0.58)$ & 12.39 \\
\hline Roumieh et al ${ }^{18}$ & PSM & & & $0.43(0.11-1.66)$ & 4.12 \\
\hline Chiang et $\mathrm{al}^{3}$ & PSM & $\bullet$ & & $0.54(0.38-0.79)$ & 54.64 \\
\hline Glaser et al ${ }^{5}$ & PSM & - & & $0.42(0.25-0.71)$ & 28.85 \\
\hline Overall $\left(I^{2}=0.0 \%, P=.427\right)$ & & & & $0.46(0.35-0.60)$ & 100.00 \\
\hline
\end{tabular}

FIGURE 4. Forest plot for reoperation. There are lower reoperation rates in the mechanical group in all studies and in the global analysis. $I^{2}=0$ indicates absence of inconsistency or heterogeneity. ES, Estimation (incidence rate ratio); CI, confidence interval; RCT, randomized control trial; PSM, propensity score-matched. 


\begin{tabular}{|c|c|c|c|c|c|}
\hline Reference & $\begin{array}{l}\text { Study } \\
\text { design }\end{array}$ & Favors mechanical & $\stackrel{\text { Favors biological }}{\longrightarrow}$ & $\mathrm{ES}(95 \% \mathrm{Cl})$ & $\begin{array}{c}\% \\
\text { Weight }\end{array}$ \\
\hline Stassano et al ${ }^{17}$ & RCT & & $\rightarrow$ & $2.33(0.60-9.02)$ & 3.21 \\
\hline Roumieh et al ${ }^{18}$ & PSM & & 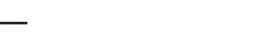 & $0.20(0.02-1.71)$ & 1.27 \\
\hline Chiang et $\mathrm{al}^{3}$ & PSM & & & $1.04(0.75-1.46)$ & 53.11 \\
\hline Glaser et $\mathrm{al}^{5}$ & PSM & & & $0.94(0.64-1.36)$ & 42.40 \\
\hline Overall $\left(I^{2}=22.2 \%, P=.278\right)$ & & & & $1.00(0.79-1.28)$ & 100.00 \\
\hline
\end{tabular}

FIGURE 5. Forest plot for stroke. Similar stroke rates between mechanical and biological groups in all studies and in the global analysis. $I^{2}=22.2$ indicates a low level of inconsistency or heterogeneity. ES, Estimation (incidence rate ratio); $C I$, confidence interval; RCT, randomized control trial; PSM, propensity score-matched.

prosthesis. Because of the small number of RCTs on this issue, a great limitation of that meta-analysis is the use of all kinds of observational studies without requiring a robust control for confounding factors.

RCTs are the gold standard for therapeutic evaluation. However, in surgery, RCTs present several practical and methodological challenges. The creation of 2 equal groups except in the treatment being evaluated assumes, in surgery, that the participating surgeon performs an operation (treatment group) as well as another (control group), which is difficult to believe and yet more difficult to verify. Recruitment is difficult and patient and surgeon masking is usually difficult and impossible, respectively. ${ }^{7,21}$

Unlike RCTs, with patient characteristics theoretically balanced in both groups, observational studies exhibit significant risk of confounding biases. PS analyses are statistical techniques for dealing with these biases. In surgery, these analyses have been increasingly used in the past 10 years $^{7}$ and some meta-analyses on the basis of these works are emerging. ${ }^{22}$ Although meta-analyses of PSM works are not methodologically as robust as RCTs, some meta-epidemiological studies have shown that they are a solid and attractive alternative in the absence of RCTs. ${ }^{7}$ In addition, PSM samples allow the reconstruction of the original databases as if they were RCTs. ${ }^{13}$

This meta-analysis confirms that patients with mechanical prostheses have lower rates of reoperation but higher rates of major bleeding than patients with biological valves. In contrast, stroke rates are similar between both groups. Long-term survival is likely to be determined according to anticoagulation-related complications and the risk of reoperation. Therefore, any setting that modifies

\begin{tabular}{|c|c|c|c|c|c|}
\hline Reference & $\begin{array}{l}\text { Study } \\
\text { design }\end{array}$ & Favors mechanical & $\underset{\longrightarrow}{\stackrel{\text { Favors biological }}{\longrightarrow}}$ & $\mathrm{ES}(95 \% \mathrm{Cl})$ & $\begin{array}{c}\% \\
\text { Weight }\end{array}$ \\
\hline Stassano et al ${ }^{17}$ & $\mathrm{RCT}$ & & - & $2.11(0.96-4.67)$ & 8.06 \\
\hline Roumieh et al ${ }^{18}$ & PSM & & & $1.50(0.42-5.32)$ & 3.17 \\
\hline Chiang et $\mathrm{al}^{3}$ & PSM & & & $1.74(1.26-2.41)$ & 48.61 \\
\hline Glaser et $\left.a\right|^{5}$ & PSM & & & $1.93(1.35-2.76)$ & 40.16 \\
\hline Overall $\left(I^{2}=0.0 \%, P=.940\right)$ & & & & $1.84(1.47-2.30)$ & 100.00 \\
\hline
\end{tabular}

FIGURE 6. Forest plot for bleeding. Stassano and colleagues ${ }^{17}$ and Roumieh and colleagues ${ }^{18}$ reported no differences. Chiang and colleagues ${ }^{3}$ and Glaser and colleagues ${ }^{5}$ reported higher bleeding rates in the mechanical group. In the global analysis higher bleeding rates were shown in the mechanical group. $I^{2}=0$ indicates absence of inconsistency or heterogeneity. ES, Estimation (incidence rate ratio); $C I$, confidence interval; $R C T$, randomized control trial; $P S M$, propensity score-matched. 
the proportion of these late complications might have an influence on survival. So, high variability of the International Normalized Ratio (INR) is a strong independent predictor of reduced survival after valve replacement and there is now evidence that INR self-management reduces INR variability and clinical events. $^{23}$ In the same way, perioperative mortality of a redo surgery or a transcatheter valve in valve procedure will have an effect on long-term survival of middle-aged patients with a bioprosthesis. In a retrospective analysis of an administrative database, Goldstone and colleagues ${ }^{4}$ have shown in a large cohort better long-term survival for patients between 45 and 54 years of age with mechanical versus biological prosthesis. However, this benefit was not found for patients between 55 and 64 years of age. Surprisingly, they observed a rate of major bleeding $(38.8 \%)$ more than twice the percentage reported by other researchers. ${ }^{3,5,6,20-22}$ This could indicate a poorly controlled INR, which could impair the survival in the mechanical group.

Other original articles have had contradictory results. Although some researchers have reported a survival benefit for patients with mechanical prosthesis, ${ }^{5,6}$ others did not find these differences. ${ }^{3}$ Interestingly, we have found no article showing that patients in this age range with biological valves live longer. However, the use of this type of prosthesis is increasing exponentially. Several reasons can be argued. First, recommendations of the most prestigious scientific societies consider that both types of prosthesis are equally reasonable for patients between 50 and 70 years of age. ${ }^{2}$ Second, reports show excellent durability of surgically implanted bioprosthesis, ${ }^{24}$ and finally, the possibility of performing a transcatheter valve in valve procedure if needed in the future. However, these 3 arguments can be refuted. Recommendations of scientific societies are not on the basis of robust and consistent evidence. ${ }^{2}$ There are works showing excellent durability of some biological prosthesis, ${ }^{24}$ but there are others showing less than optimal durability, even for the same prosthesis. ${ }^{25}$ Transcatheter valve in valve procedures might be an attractive strategy for structural valve deterioration but perioperative mortality has been consistently similar to redo surgery and long-term data are lacking. ${ }^{26}$ Moreover, risk of death due to prosthesis degeneration is more complex than the simple risk of reoperation. So, we have previously shown that only a small percentage of the patients with degenerated bioprosthesis are reoperated and this degeneration leads to a 4.5 -fold increase in the risk of death. ${ }^{25}$ An unexpected, unpredictable, accelerated, explosive, and life-threating pattern of structural valve deterioration has been shown for some biological prostheses. ${ }^{27}$ This risk would be completely avoided by implanting a mechanical prosthesis.
Therefore, this meta-analysis is the best available evidence on this topic. It shows that, despite not having the possibility of a transcatheter valve in valve, mechanical prostheses are associated with better long-term survival than biological valves for this age range.

\section{Strengths of the Study Design}

To our knowledge, this is the first meta-analysis of RCT and PSM studies comparing long term survival of middle-aged patients with mechanical versus biological aortic prosthesis. The use exclusively of RCT and PSM samples should provide a real estimate of the risk of death. We performed a simulation of an individual-level meta-analysis reconstructing the database of each study and pooling all of them into one. This allowed us to reconstruct reliably and accurately the Kaplan-Meier survival curves and the hazard function as if it were a patient-level meta-analysis. The random effects model provides a conservative estimate of the pooled effect size but it can hide heterogeneity. For this reason we decided to use the fixed effect model so we could make sure that the included studies were consistent.

\section{Limitation}

This meta-analysis has limitations. The use of PSM samples limits the number of articles and the sample size that could have been analyzed. In fact, some important and well known studies could not be included. ${ }^{4}$ Because of the small number of studies analyzed, the evaluation of the publication bias is limited. PSM trials are a good alternative when RCTs are difficult to achieve but, unlike RCTs, they cannot control for unknown or unmeasured variables. Therefore, we recognize that even the best PSM studies can be biased but, even in the best-case scenario, the most recent modification of the American guidelines ${ }^{2}$ could only be on the basis of this kind of study. Mechanical aortic prostheses are implanted in patients expected to live longer, and the long-term survival can be affected by general conditions that are not captured by any measured variable. Future works and meta-analyses comparing mechanical prosthesis with the Ross procedure, where the similarity in life expectancy is usually more respected, could shed light on this issue.

Moreover, we performed an approximation to an individual-level meta-analysis reconstructing the original databases. However a real patient-level meta-analysis of RCT data has more alternatives and provides greater level of evidence.

\section{CONCLUSIONS}

We performed a meta-analysis of RCT and PSM works. The 5 studies analyzed present consistent results and provide robust evidence supporting the use of mechanical 
aortic prosthesis in patients between 50 and 70 years of age. The difference in survival is small, begins in the first years, and is maintained during 15 years of follow-up.

\section{Conflict of Interest Statement}

Authors have nothing to disclose with regard to commercial support.

\section{References}

1. Head SJ, Celik M, Kappetein AP. Mechanical versus bioprosthetic aortic valve replacement. Eur Heart J. 2017;38:2183-91.

2. Nishimura RA, Otto CM, Bonow RO, Carabello BA, Erwin JP, Fleisher LA, et al. 2017 AHA/ACC Focused update of the 2015 AHA/ACC guideline for the management of patients with valvular heart disease: a report of the American College of Cardiology/American Heart Association Task Force on clinical practice guidelines. J Am Coll Cardiol. 2017;70:252-89.

3. Chiang YP, Chikwe J, Moskowitz AJ, Itagaki S, Adams DH, Egorova NN. Survival and long term outcomes following bioprosthetic vs mechanical aortic valve replacement in patients aged 50 to 69 years. JAMA. 2014;312: 1323-9.

4. Goldstone AB, Chiu P, Baiocchi M, Lingala B, Patrick WL, Fischbein MP, et al. Mechanical or biologic prostheses for aortic-valve and mitral-valve replacement. N Engl J Med. 2017:377:1847-57.

5. Glaser N, Jackson V, Holzmann MJ, Franco-Cereceda A, Sartipy U. Aortic valve replacement with mechanical vs biological prostheses in patients aged 50-69 years. Eur Heart J. 2016;37:2658-67.

6. Brown ML, Schaff HV, Lahr BD, Mullany CJ, Sundt TM, Dearany JA, et al. Aortic valve replacement in patients aged 50-70 years: improved outcome with mechanical versus biologic prostheses. J Thorac Cardiovasc Surg. 2008;135: 878-84.

7. Lonjon G, Boutron I, Trinquart L, Ahmad N, Aim F, Nizard R, et al. Comparison of treatment effects estimates from prospective non randomized studies with propensity score analysis and randomized controlled trials of surgical procedures. Ann Surg. 2014;259:18-25.

8. Austin PC. An introduction to propensity score methods for reducing the effects of confounding in observational studies. Multivariate Behav Res. 2011;46: 399-424.

9. Deb S, Austin PC, Tu JV, Ko DT, Mazer CD, Kiss A, et al. A review of propensity-score methods and their use in cardiovascular research. Can J Cardiol. 2016;32:259-65.

10. Moher D, Liberati A, Tetzlaff J, Altman DG, PRISMA Group. Preferred reporting items for systematic reviews and meta-analyses: the PRISMA statement. J Clin Epidemiol. 2009;62:1006-12.

11. Higgins JP, Sterne JA, Savović J, Page MJ, Hróbjartsson A, Boutron I, et al. A revised tool for assessing risk of bias in randomized trials. In: Chandler J, McKenzie J, Boutron I, Welch V, eds. Cochrane Methods. Cochrane Database of Systematic Reviews. 2016, Issue 10 (Suppl 1). dx.doi.org/10.1002/ 14651858.CD201601. Available at: http://www.riskofbias.info. Accessed April 21, 2018.
12. Sterne JA, Hernan MA, Reeves BC, Savovic J, Berkman ND, Viswanathan M, et al. ROBINS-I: a tool for assessing risk of bias in non-randomized studies of interventions. BMJ. 2016;355:i4919.

13. Wei Y, Royston P. Reconstructing time-to-event data from published Kaplan-Meier curves. Stata J. 2017;17:786-802.

14. Harbord RM, Egger M, Sterne JA. A modified test for small-study effects in meta-analyses of controlled trials with binary endpoints. Stat Med. 2006;25: 3443-57.

15. Peters JL, Sutton AJ, Jones DR, Abrams KR, Rushton L. Comparison of two methods to detect publication bias in meta-analysis. JAMA. 2006;295: 676-80.

16. Austin PC, Lee DS, Fine JP. Introduction to the analysis of survival data in the presence of competing risks. Circulation. 2016;133:601-9.

17. Stassano P, Di Tommaso L, Monaco M, Iorio F, Pepino P, Spampinato N, et al Aortic valve replacement: a prospective randomized evaluation of mechanical versus biological valves in patients ages 55 to 70 years. J Am Coll Cardiol. 2009;54:1862-8.

18. Roumieh M, Ius F, Tudorache I, Ismail I, Fleissner F, Haverich A, et al. Comparison between biological and mechanical aortic valve prostheses in middle-aged patients matched through propensity score analysis: long-term results. Eur J Cardiothorac Surg. 2015;48:129-36.

19. Sakamoto Y, Yoshitake M, Matsumura Y, Naruse H, Bando K, Hashimoto K Choice of aortic valve prosthesis in a rapidly aging and long-living society. Ann Thorac Cardiovasc Surg. 2016;22:333-9.

20. Zhao DF, Seco M, Wu JJ, Edelman JB, Wilson MK, Vallely MP, et al. Mechanical versus bioprosthetic aortic valve replacement in middle-aged adults: a systematic review and meta-analysis. Ann Thorac Surg. 2016;102:315-27.

21. Mansournia MA, Higgins JP, Sterne JA, Hernan MA. Biases in randomized trials: a conversation between trialists and epidemiologists. Epidemiology. 2017;28 $54-9$

22. Gaudino M, Puskas JD, Di Franco A, Ohmes LB, Iannaccone M, Barbero U Three arterial grafts improve late survival: a meta-analysis of propensitymatched studies. Circulation. 2017;135:1036-44.

23. Baumgartner H, Falk V, Bax JJ, De Bonis M, Hamm C, Holm PJ. 2017 ESC/ EACTS guidelines for the management of valvular heart disease. Eur Heart J. 2017;38:2739-91.

24. Yankah CA, Pasic M, Musci M, Stein J, Detschades C, Siniawski H. Aortic valve replacement with the Mitroflow pericardial bioprosthesis: durability results up to 21 years. J Thorac Cardiovasc Surg. 2008;136:688-96.

25. Díaz R, Hernández-Vaquero D, Silva J, Pascual I, de la Hera JM, Leon V, et al. Real structural valve deterioration of the Mitroflow aortic prosthesis: competing risk analysis. Rev Esp Cardiol (Engl Ed). 2017;70:1074-81.

26. Pahn K, Zhao DF, Wang N, Huo YR, Di Eusanio M, Yan TD. Transcatheter valve-in-valve implantation versus reoperative conventional aortic valve replacement: a systematic review. J Thorac Dis. 2016;8:E83-93.

27. Sénage T, Le Tourneau T, Foucher Y, Pattier S, Cueff C, Michel M, et al. Early structural valve deterioration of Mitroflow aortic bioprosthesis: mode, incidence, and impact on outcome in a large cohort of patients. Circulation. 2014;130; $2012-20$

Key Words: aortic valve replacement, biological prosthesis, long-term survival 


\section{APPENDIX E1. METHODS}

This meta-analysis was conceived and prepared in 2017. A prespecified protocol was created, for which the summary can be scrutinized in PROSPERO (https://www.crd.york.ac. uk/PROSPERO). On September 10, 2017 we submitted our systematic review in PROSPERO. On October 25, 2017 the PROSPERO editors accepted our article and was published on their Web site with the registration number: CRD42017076611. In May 2018 we submitted an update and in June 2018 we reported that this meta-analysis was completed.

This work was performed according to the Preferred Reporting Items for Systematic Reviews and Meta-Analyses guidelines. Because of the lack of quality of old metaanalyses, an international group developed a guidance called the QUality Of Reporting Of Meta-analyses statement. In 2009, a revision of that guideline was published. This revision, named Preferred Reporting Items for Systematic Reviews and Meta-Analyses, provides several recommendations to plan, elaborate, and report a systematic review and meta-analysis. ${ }^{\mathrm{E}}$

\section{Search Strategy}

The following searches were performed using PubMed:

1. Free text search: biological mechanical aortic prosthesis

Query translation: ("biology" [MeSH Terms] OR "biology"[All Fields] OR "biological"[All Fields]) AND mechanical[All Fields] AND ("aorta" [MeSH Terms] OR "aorta"[All Fields] OR "aortic"[All Fields]) AND ("prosthesis implantation" [MeSH Terms] OR ("prosthesis"[All Fields] AND "implantation" [All Fields]) OR "prosthesis implantation"[All Fields] OR "prosthesis"[All Fields] OR "prostheses and implants" [MeSH Terms] OR ("prostheses"[All Fields] AND "implants"[All Fields]) OR "prostheses and implants"[All Fields])

2. Free text search: biological mechanical aortic valve

Query translation: ("biology" [MeSH Terms] OR "biology"[All Fields] OR "biological"[All Fields]) AND mechanical[All Fields] AND ("aortic valve" [MeSH Terms] OR ("aortic"[All Fields] AND "valve"[All Fields]) OR "aortic valve"[All Fields])

3. Free text search: mechanical bioprosthetic aortic valve

Query translation: mechanical[All Fields] AND bioprosthetic[All Fields] AND ("aortic valve" [MeSH Terms] OR ("aortic"[All Fields] AND "valve"[All Fields]) OR “aortic valve”[All Fields])
4. Free text search: mechanical biological prosthetic valve

Query translation: mechanical[All Fields] AND ("biology"[MeSH Terms] OR "biology"[All Fields] OR "biological"[All Fields]) AND prosthetic[All Fields] AND valve[All Fields]

5. Free text search: mechanical biologic aortic valve

Query translation: mechanical[All Fields] AND ("biology"[MeSH Terms] OR "biology"[All Fields] OR "biologic"[All Fields]) AND ("aortic valve" [MeSH Terms] OR ("aortic"[All Fields] AND "valve"[All Fields]) OR "aortic valve"[All Fields])

6. Free text search: tissue valve mechanical aortic valve

Query translation: ("tissues" [MeSH Terms] OR "tissues"[All Fields] OR "tissue" [All Fields]) AND valve [All Fields] AND mechanical[All Fields] AND ("aortic valve"[MeSH Terms] OR ("aortic"[All Fields] AND "valve"[All Fields]) OR "aortic valve"[All Fields])

7. Free text search: mechanical biologic aortic prosthesis

Query translation: mechanical[All Fields] AND ("biology" [MeSH Terms] OR "biology"[All Fields] OR "biologic"[All Fields]) AND ("aorta" [MeSH Terms] OR "aorta"[All Fields] OR "aortic"[All Fields]) AND ("prosthesis implantation" [MeSH Terms] OR ("prosthesis"[All Fields] AND "implantation" [All Fields]) OR "prosthesis implantation"[All Fields] OR "prosthesis"[All Fields] OR "prostheses and implants" [MeSH Terms] OR ("prostheses"[All Fields] AND "implants"[All Fields]) OR "prostheses and implants"[All Fields])

8. Free text search: mechanical tissue valve aortic prosthesis

Query translation: mechanical[All Fields] AND ("tissues" [MeSH Terms] OR "tissues"[All Fields] OR "tissue"[All Fields]) AND valve[All Fields] AND ("aorta" [MeSH Terms] OR "aorta"[All Fields] OR "aortic"[All Fields]) AND ("prosthesis implantation"'[MeSH Terms] OR ("prosthesis" [All Fields] AND “implantation"[All Fields]) OR "prosthesis implantation" [All Fields] OR "prosthesis" [All Fields] OR "prostheses and implants"[MeSH Terms] OR ("prostheses"[All Fields] AND "implants"[All Fields]) OR "prostheses and implants"[All Fields]) 
9. Free text search: mechanical bioprosthesis aortic valve

Query translation: mechanical[All Fields] AND ("bioprosthesis" [MeSH Terms] OR "bioprosthesis"[All Fields]) AND ("aortic valve" [MeSH Terms] OR ("aortic"[All Fields] AND "valve"[All Fields]) OR “aortic valve"[All Fields])

\section{Election of the Studies}

Two reviewers (D.H.-V. and R.D.) performed the search and independently reviewed titles and abstract to exclude articles that could not fulfill the inclusion criteria. Finally, the references of the articles that could meet the inclusion criteria were given to another researcher (I.P.), who was asked to print the article, remove the Introduction, Discussion, and Conclusion sections and hide the journal identification, author name(s), measure of the association, and labels of the Kaplan-Meier curve. Then, these articles (basically, the Methods and Results) were independently evaluated by D.H.-V. and R.D., who decided which articles met all of the inclusion criteria. In case of disagreement, another independent researcher (P.A.) made the decision. In the case of overlapping samples, the longest follow-up was selected.

\section{Data Extraction}

Data extraction was performed for articles meeting inclusion criteria by 2 independent authors (I.P. and P.A.). An established form on the basis of the Cochrane Collaboration was created. ${ }^{\mathrm{E} 2}$ Authors, study design, study period, date of publication, country, mean, median, and maximum follow-up were registered. The following patient characteristics were also documented for both groups: age, male sex, diabetes mellitus, renal failure, extracardiac arteriopathy, endocarditis, New York Heart Association functional class, left ventricular dysfunction, and urgent/emergent surgery.

\section{Statistical Analysis}

The period that an individual remains free of an adverse outcome can be of utmost importance. So, the HR is often recommended as the most appropriate associate measure for the analysis of studies with time to event outcomes. ${ }^{\text {E3 }}$ In a meta-analysis of aggregated time to event data across trials, an essential step is to extract the (log) HR and its variance from published trials. An approximation to HR can be derived by a "curve approach," as described by Tierney and colleagues. ${ }^{\mathrm{E} 4}$ The curve approach was extended ${ }^{\mathrm{E} 5}$ beyond the estimation of HR to the reconstruction of time to event data at the individual level and Wei and colleagues ${ }^{\mathrm{E} 6}$ reported the implementation of this algorithm with improvements. In this meta-analysis we performed this last analysis, which allows reconstruction of the original databases and to pool them into one, mimicking an individual-level meta- analysis. HR, life tables, and survival curves can be easily constructed for the global sample, the sequence of outcomes and the incidence function can be analyzed properly and might well lead to a better understanding of the disease and treatments under investigation. ${ }^{\mathrm{E} 5}$ So, we did not depend on the possibility that the authors did not provide us with additional data. Therefore, authors were not contacted.

\section{RESULTS}

A subgroup analysis (50-60 years of age and 60-70 years of age) was considered but the small number of studies analyzed prevented us from doing it. In addition, it was considered to calculate an estimation of the number of unpublished studies as a measure of publication bias (Gleser-Olkin test) but the small number of studies analyzed prevented us from doing it.

This is the list of the 34 full-text articles that were reviewed and excluded:

\section{Age out of Range $(n=25)$}

1. Zhibing Q, Xin C, Ming X, Lele L, YingShuo J, LiMing W. Should bioprostheses be considered the valve of choice for dialysis-dependent patients? $J$ Cardiothorac Surg. 2013;8:42.

2. Williams ML, Bavaria JE, Acker MA, Desai ND, Vallabhajosyula P, Hargrove C, et al. Valve selection in end-stage renal disease: should it always be biological? Ann Thorac Surg. 2016;102:1531-5.

3. Weber A, Noureddine H, Englberger L, Dick F, Gahl $\mathrm{B}$, Aymard T, et al. Ten-year comparison of pericardial tissue valves versus mechanical prostheses for aortic valve replacement in patients younger than 60 years of age. J Thorac Cardiovasc Surg. 2012;144:1075-83.

4. Waszyrowski T, Kasprzak JD, Krzemińska-Pakuła M, Dziatkowiak A, Zasłonka J. Early and longterm outcome of aortic valve replacement with homograft versus mechanical prosthesis-8-year follow-up study. Clin Cardiol. 1997;20:843-8.

5. Toole JM, Stroud MR, Kratz JM, Crumbley AJ, Crawford FA, Ikonomidis JS. Valve surgery in renal dialysis patients. J Heart Valve Dis. 2006;15:453-8.

6. Prifti E, Bonacchi M, Ademaj F, Giunti G, Esposito $\mathrm{G}$, Baboci A, et al. Early and mid-term outcome in terms of functional and hemodynamic performance of the St Jude regent 19-mm aortic mechanical prosthesis versus 19-mm Carpentier Edwards aortic biological prosthesis. $J$ Cardiothorac Surg. 2015;10:154.

7. Polomsky M, Kilgo PD, Puskas JD, Halkos ME, Thourani VH, Kelli HM, et al. Long-term survival for patients with metabolic syndrome after bioprosthetic or mechanical valve replacement. $J$ Card Surg. 2014;29:26-34. 
8. Peterseim DS, Cen YY, Cheruvu S, Landolfo K, Bashore TM, Lowe JE, et al. Long-term outcome after biologic versus mechanical aortic valve replacement in 841 patients. $J$ Thorac Cardiovasc Surg. 1999;117:890-7.

9. Pantaleo A, Murana G, Di Marco L, Jafrancesco G, Barberio G, Berretta P, et al. Biological versus mechanical Bentall procedure for aortic root replacement: a propensity score analysis of a consecutive series of 1112 patients. Eur J Cardiothorac Surg. 2017;52:143-9.

10. Oxenham H, Bloomfield P, Wheatley DJ, Lee RJ, Cunningham J, Prescott RJ, et al. Twenty year comparison of a Bjork-Shiley mechanical heart valve with porcine bioprostheses. Heart. 2003;89:715-21.

11. Niclauss L, von Segesser LK, Ferrari E. Aortic biological valve prosthesis in patients younger than 65 years of age: transition to a flexible age limit? Interact Cardiovasc Thorac Surg. 2013;16:501-7.

12. Nguyen DT, Delahaye F, Obadia JF, Duval X, Selton-Suty C, Carteaux JP, et al. Aortic valve replacement for active infective endocarditis: 5 -year survival comparison of bioprostheses, homografts and mechanical prostheses. Eur J Cardiothorac Surg. 2010;37:1025-32.

13. Myken P, Caidahl K, Larsson P, Larsson S, Wallentin I, Berggren H. Mechanical versus biological valve prosthesis - a 10-year comparison regarding function and quality-of-life. Ann Thorac Surg. 1995;60:S447-52.

14. Lucke JC, Samy RN, Atkins BZ, Silvestry SC, Douglas JM, Schwab SJ, et al. Results of valve replacement with mechanical and biological prostheses in chronic renal dialysis patients. Ann Thorac Surg. 1997;64:129-32.

15. Kawachi Y, Tokunaga K. Preferability of bioprostheses for isolated aortic-valve replacement - a comparative-study between mechanical and bioprosthetic valves. Jpn Circ J. 1990;54:137-45.

16. Inaba $H$, Higuchi $K$, Koseni $K$, Ohsawa $H$, Kinoshita O, Funatogawa K, et al. Outcomes and hemodynamics after aortic valve replacement: a comparison of stentless versus mechanical valves. Ann Thorac Cardiovasc Surg. 2007;13:165-71.

17. Hwang MH, Burchfiel CM, Sethi GK, Oprian C, Grover FL, Henderson WG, et al. Comparison of the causes of late death following aortic and mitral valve replacement. VA co-operative study on valvular heart disease. J Heart Valve Dis. 1994;3:17-24.

18. Hellgren L, Granath F, Ekbom A, Stahle E. Biological versus mechanical prosthesis in 3279 patients from the Swedish in-patients register. Scand Cardiovasc J. 2011;45:223-8.
19. Hammermeister K, Sethi G, Henderson W, Oprian C, Kim T, Rahimtoola S. A comparison of outcomes in men 11 years after heart-valve replacement with a mechanical valve or bioprosthesis. $N$ Engl J Med. 1993;328:1289-96.

20. Hammermeister K, Sethi GK, Henderson WG, Grover FL, Oprian C, Rahimtoola SH. Outcomes 15 years after valve replacement with a mechanical versus a bioprosthetic valve: final report of the Veterans Affairs randomized trial. J Am Coll Cardiol. 2000;36:1152-8.

21. Fradet G, Jamieson W, Abel J, Lichtenstein S, Miyagishima $\mathrm{R}$, Ling $\mathrm{H}$, et al. Clinical-performance of biological and mechanical prostheses. Ann Thorac Surg. 1995;60:S453-8.

22. Feyrer R, Lott S, Englmann P, von der Emde J. Results of a 1 to 31 years follow-up after aortic valve replacement in 2327 patients. J Cardiovasc Surg (Torino). 1996;37(6 suppl 1):17-22.

23. de Almeida AS, Picon PD, Belmonte Wender OC. Outcomes of patients subjected to aortic valve replacement surgery using mechanical or biological prostheses. Rev Bras Cir Cardiovasc. 2011;26:326-37.

24. Byrne JG, Gudbjartsson T, Karavas AN, Mihaljevic T, Phillips BJ, Aranki SF, et al. Biological vs. mechanical aortic root replacement. Eur J Cardiothorac Surg. 2003;23:305-10.

25. Boening A, Boedeker RH, Rosendahl UP, Niemann B, Haberer S, Roth P, et al. Long-term results of mechanical and biological heart valves in dialysis and non-dialysis patients. Thorac Cardiovasc Surg. 2011;59:454-9.

\section{No Propensity Score-Matched Methods}

1. Prasongsukarn K, Jamieson WR, Germann E, Chan F, Lichtenstein SV. Aortic and mitral prosthetic valve replacement in age groups 61-65 \& 66-70 years. Asian Cardiovasc Thorac Ann. 2007;15:127-33.

2. Nishida T, Sonoda H, Oishi Y, Tatewaki H, Tanoue Y, Shiokawa Y, et al. Long-term results of aortic valve replacement with mechanical prosthesis or CarpentierEdwards Perimount bioprosthesis in Japanese patients according to age. Circ J. 2014;78:2688-95.

3. Minakata K, Tanaka S, Tamura N, Yanagi S, Ohkawa Y, Okonogi S, et al. Comparison of the long-term outcomes of mechanical and bioprosthetic aortic valves a propensity score analysis. Circ J. 2017;81:1198-206.

4. Kulik A, Bedard P, Lam BK, Rubens FD, Hendry PJ, Masters RG, et al. Mechanical versus bioprosthetic valve replacement in middle-aged patients. Eur $J$ Cardiothorac Surg. 2006;30:485-91.

5. Tokunaga S, Tominaga R. Selection of the prosthesis for aortic valve replacement: mechanical or bio? [in 
Japanese]. Nihon Geka Gakkai Zasshi. 2007;108: 64-8.

6. Hanania G, Michel PL, Montély JM, Warembourg H, Nardi O, Leguerrier A, et al. The long term (15 years) evolution after valvular replacement with mechanical prosthesis or bioprosthesis between the age of 60 and 70 years [in French]. Arch Mal Coeur Vaiss. 2004;97:7-14.

7. Goldstone AB, Chiu P, Baiocchi M, Lingala B, Patrick WL, Fischbein MP, et al. Mechanical or biologic prostheses for aortic-valve and mitral-valve replacement. $N$ Engl J Med. 2017;377:1847-57.

8. Carrier M, Pellerin M, Perrault LP, Pagé P, Hébert Y, Cartier R, et al. Aortic valve replacement with mechanical and biologic prosthesis in middle-aged patients. Ann Thorac Surg. 2001;71(5 suppl):S253-6.

9. Brown ML, Schaff HV, Lahr BD, Mullany CJ, Sundt TM, Dearani JA, et al. Aortic valve replacement in patients aged 50 to 70 years: improved outcome with mechanical versus biologic prostheses. J Thorac Cardiovasc Surg. 2008;135:878-84.

\section{Definitions of Stroke and Bleeding Events According to the Individual Studies}

Stassano and Colleagues ${ }^{17}$

Bleeding event: episode of major internal or external bleeding that causes death, hospitalization, or permanent injury or necessitates transfusion.

Stroke: prolonged ( $>72$ hours) or permanent neurologic deficit that is usually associated with abnormal results of magnetic resonance imaging or computed tomography scans. Patients with minimal, atypical, or protean symptoms that lead to radiographic imaging showing an acute ischemic event are considered to have sustained a stroke.

Roumieh and Colleagues ${ }^{18}$

Bleeding event: episode of major internal or external bleeding that causes death, hospitalization, or permanent injury or necessitates transfusion.

Stroke: prolonged ( $>72$ hours) or permanent neurologic deficit that is usually associated with abnormal results of magnetic resonance imaging or computed tomography scans. Patients with minimal, atypical, or protean symptoms that lead to radiographic imaging showing an acute ischemic event are considered to have sustained a stroke.

Chiang and Colleagues ${ }^{3}$

Bleeding event according to International Classification of Diseases Ninth Revision ICD-9:
430 Subarachnoid hemorrhage

431 Intracerebral hemorrhage

432 Other and unspecified intracranial hemorrhage

432.0 Nontraumatic extradural hemorrhage

432.1 Subdural hemorrhage

432.9 Unspecified intracranial hemorrhage

423.0 Hemopericardium

423.1 Adhesive pericarditis

423.2 Constrictive pericarditis

423.3 Cardiac tamponade convert

456.0 Esophageal varices with bleeding

456.20 Esophageal varices in diseases classified elsewhere, with bleeding

459.0 Hemorrhage, unspecified

530.21 Ulcer of esophagus with bleeding

531.0 Acute gastric ulcer with hemorrhage

531.00 Acute gastric ulcer with hemorrhage, without mention of obstruction

531.01 Acute gastric ulcer with hemorrhage, with obstruction

531.2 Acute gastric ulcer with hemorrhage and perforation

531.20 Acute gastric ulcer with hemorrhage and perforation, without mention of obstruction

531.21 Acute gastric ulcer with hemorrhage and perforation, with obstruction

532.0 Acute duodenal ulcer with hemorrhage

532.00 Acute duodenal ulcer with hemorrhage, without mention of obstruction convert

532.01 Acute duodenal ulcer with hemorrhage, with obstruction

532.2 Acute duodenal ulcer with hemorrhage and perforation

532.20 Acute duodenal ulcer with hemorrhage and perforation, without mention of obstruction

532.21 Acute duodenal ulcer with hemorrhage and perforation, with obstruction

533.0 Acute peptic ulcer of unspecified site with hemorrhage

Stroke: According to the International Classification of Diseases Ninth Revision:

430 Subarachnoid hemorrhage

431 Intracerebral hemorrhage

432 Other and unspecified intracranial hemorrhage

432.0 Nontraumatic extradural hemorrhage 
432.1 Subdural hemorrhage

432.9 Unspecified intracranial hemorrhage

433.01 Occlusion and stenosis of basilar artery with cerebral infarction

433.11 Occlusion and stenosis of carotid artery with cerebral infarction

433.21 Occlusion and stenosis of vertebral artery with cerebral infarction

433.31 Occlusion and stenosis of multiple and bilateral precerebral arteries with cerebral infarction

433.81 Occlusion and stenosis of other specified precerebral artery with cerebral infarction

433.91 Occlusion and stenosis of unspecified precerebral artery with cerebral infarction

434.01 Cerebral thrombosis with cerebral infarction

434.11 Cerebral embolism with cerebral infarction

434.91 Cerebral artery occlusion, unspecified with cerebral infarction

997.02 Iatrogenic cerebrovascular infarction or hemorrhage

Glaser and colleagues ${ }^{5}$ :

Bleeding event according to the International Classification of Diseases 10th Revision

D629 Acute posthemorrhagic anemia

I60 Nontraumatic subarachnoid hemorrhage

I61 Nontraumatic intracerebral hemorrhage

I62 Other and unspecified nontraumatic intracranial hemorrhage

I85.0 Esophageal varices

K22.6 Gastro-esophageal laceration-hemorrhage syndrome

K25.0 Acute gastric ulcer with hemorrhage

K25.2 Acute gastric ulcer with both hemorrhage and perforation

K25.4 Chronic or unspecified gastric ulcer with hemorrhage

K25.6 Chronic or unspecified gastric ulcer with both hemorrhage and perforation

K26.0 Acute duodenal ulcer with hemorrhage

K26.2 Acute duodenal ulcer with both hemorrhage and perforation

K26.4 Chronic or unspecified duodenal ulcer with hemorrhage
K26.6 Chronic or unspecified duodenal ulcer with both hemorrhage and perforation

K27.0 Acute peptic ulcer, site unspecified, with hemorrhage

K27.2 Acute peptic ulcer, site unspecified, with both hemorrhage and perforation

K27.4 Chronic or unspecified peptic ulcer, site unspecified, with hemorrhage

K27.6 Chronic or unspecified peptic ulcer, site unspecified, with both hemorrhage and perforation

K28.0 Acute gastrojejunal ulcer with hemorrhage

K28.2 Acute gastrojejunal ulcer with both hemorrhage and perforation

K28.4 Chronic or unspecified gastrojejunal ulcer with hemorrhage

K28.6 Chronic or unspecified gastrojejunal ulcer with both hemorrhage and perforation

K29.0 Acute gastritis

K62.5 Hemorrhage of anus and rectum

K92.0 Hematemesis

K92.1 Melena

K92.2 Gastrointestinal hemorrhage, unspecified

I31.2 Hemopericardium, not elsewhere classified

I23.0 Hemopericardium as current complication following acute myocardial infarction

J94.2 Hemothorax

K66.1 Hemoperitoneum

M25.0 Hemarthrosis

N42.1 Congestion and hemorrhage of prostate

N501A: Hemorrhage of male genital organs

N93.8 Other specified abnormal uterine and vaginal bleeding

N93.9 Abnormal uterine and vaginal bleeding, unspecified

N95.0 Postmenopausal bleeding

R04.1 Hemorrhage from throat

R04.2 Hemoptysis

R04.8 Hemorrhage from other sites in respiratory passages

R04.9 Hemorrhage from respiratory passages, unspecified

R31 Hematuria

Stroke: According to the International Classification of Diseases 10th Revision

I60 Nontraumatic subarachnoid hemorrhage 
I61 Nontraumatic intracerebral hemorrhage

I62 Other and unspecified nontraumatic intracranial hemorrhage

I63 Cerebral infarction

Sakamoto and Colleagues ${ }^{19}$

Bleeding event: episode of major internal or external bleeding that causes death, hospitalization, or permanent injury or necessitates transfusion.

Stroke: prolonged ( $>72$ hours) or permanent neurologic deficit that is usually associated with abnormal results of magnetic resonance imaging or computed tomographic scans. Patients with minimal, atypical, or protean symptoms that lead to radiographic imaging showing an acute ischemic event are considered to have sustained a stroke.

Reconstructed survival curves are shown in Figures E1E5. Hazards proportionality was assessed for each trial and for the overall sample by calculating the test on the basis of Shoenfeld residuals. $P$ value was for the global sample was 0.83 ; Roumieh and colleagues, ${ }^{18} P=.76$; Stassano and colleagues, ${ }^{17} P=.72$; Sakamoto and colleagues, ${ }^{19}$ $P=.51$; Glaser and colleagues, ${ }^{5} P=.87$; and Chiang and colleagues, ${ }^{3} P=.94$

\section{Pooled Analysis For Late Survival With Aggregated Data}

Pooled analysis on the basis of fixed effect inverse variance method was consistent with the patient-level meta-analysis and showed significant differences favoring the mechanical group (HR, 0.88; 95\% confidence interval, 0.78-0.98; $P=.02$; Figure E7). Calculations to detect heterogeneity showed consistency between studies. Q test had a $P$-value $=.41$ and $I^{2}=0 \%$. Galbraith plot confirmed these findings (Figure E8). There was no sign of publication bias, Harbord test with $P=.76$ and Peter test with $P=.82$. Funnel and Harbord plots are shown in Figures E9 and E10.

Table E2 shows information on sensitivity and influential analysis and Table E3 shows the cause of death for each individual study.

\section{PRIMARY OBJECTIVES \\ Survival Estimates}

Figure E1 shows the reconstructed Kaplan-Meier survival curves of Stassano and colleagues. ${ }^{17}$ Figure E2 shows the reconstructed Kaplan-Meier survival curves of Roumieh and colleagues. ${ }^{18}$ Figure E3 shows the reconstructed Kaplan-Meier survival curves of Chiang and colleagues. ${ }^{3}$ Figure E4 shows the reconstructed Kaplan-Meier survival curves of Glaser and colleagues. ${ }^{5}$ Figure E5 shows the reconstructed Kaplan-Meier survival curves of Sakamoto and colleagues. ${ }^{19}$ Figure E6 shows the smoothed hazard function of the global sample.

\section{Late Survival}

Figure E7 shows a Forest plot for late survival with aggregated data. Figure E8 shows a Galbraith plot to assess heterogeneity. Studies between the red lines indicate consistency. Figure E9 shows a funnel plot to assess publication bias. Studies between the red lines indicate no publication bias. Figure E10 shows a Harbord plot to assess publication bias. Studies between the confidence interval indicate no publication bias.

\section{SECONDARY OBJECTIVES \\ Reoperation}

Figure E11 shows a Galbraith plot to assess heterogeneity. Studies between the red lines indicate consistency. Figure E12 shows a funnel plot to assess publication bias. Studies between the red lines indicate no publication bias. Figure E13 shows a Harbord plot to assess publication bias. Studies between the confidence interval indicate no publication bias.

\section{Stroke}

Figure E14 shows a Galbraith plot to assess heterogeneity. Studies between the red lines indicate consistency. Figure E15 shows a funnel plot to assess publication bias. Studies between the red lines indicate no publication bias. Figure E16 shows a Harbord plot to assess publication bias. Studies between the confidence interval indicate no publication bias.

\section{Major Bleeding}

Figure E17 shows a Galbraith plot to assess heterogeneity. Studies between the red lines indicate consistency. Figure E18 shows a funnel plot to assess publication bias. Studies between the red lines indicate no publication bias. Figure E19 shows a Harbord plot to assess publication bias. Studies between the confidence interval indicate no publication bias.

\section{E-References}

E1. Moher D, Liberati A, Tetzlaff J, Altman DG, The PRISMA Group. Methods of systematic reviews and meta-analysis: preferred reporting items for systematic reviews and meta-analyses: the PRISMA statement. J Clin Epidemiol. 2009; 62:1006-12.

E2. Cochrane Training. Cochrane handbook for systematic review of interventions. Version 5.1. The Cochrane Collaboration. Available at: http://handbook-5-1. cochrane.org. Accessed September 1, 2017.

E3. Deeks JJ, Higgins JP, Altman DG. Analysing data and undertaking meta-analyses. In: Higgins JPT, Green S, eds. Cochrane Handbook for Systematic Reviews of Interventions. Chichester, UK: Wiley; 2008:243-96.

E4. Tierney JF, Stewart LA, Ghersi D, Burdett S, Sydes MR. Practical methods for incorporating summary time-to-event data into meta-analysis. Trials. 2007;8:16.

E5. Guyot P, Ades AE, Ouwens MJ, Welton NJ. Enhanced secondary analysis of survival data: reconstructing the data from published Kaplan-Meier survival curves. BMC Med Res Methodol. 2012;12:9.

E6. Wei Y, Royston P. Reconstructing time-to-event data from published KaplanMeier curves. Stata J. 2017;17:786-802. 


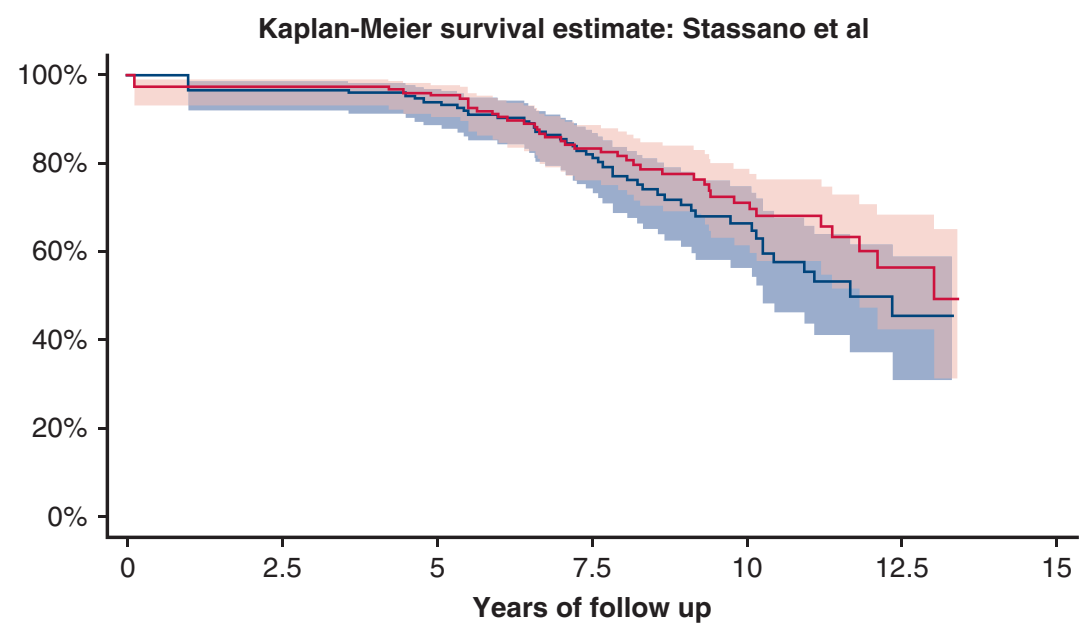

Number at risk

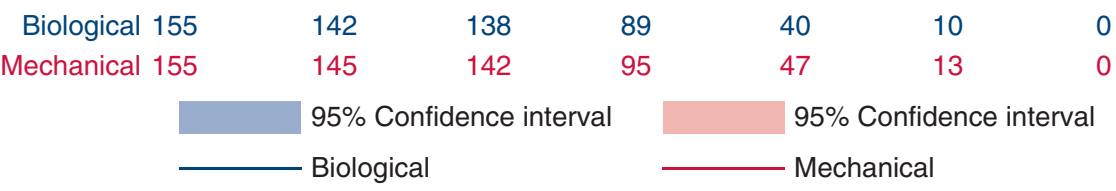

FIGURE E1. Reconstructed Kaplan-Meier survival curves of Stassano and colleagues. ${ }^{17}$

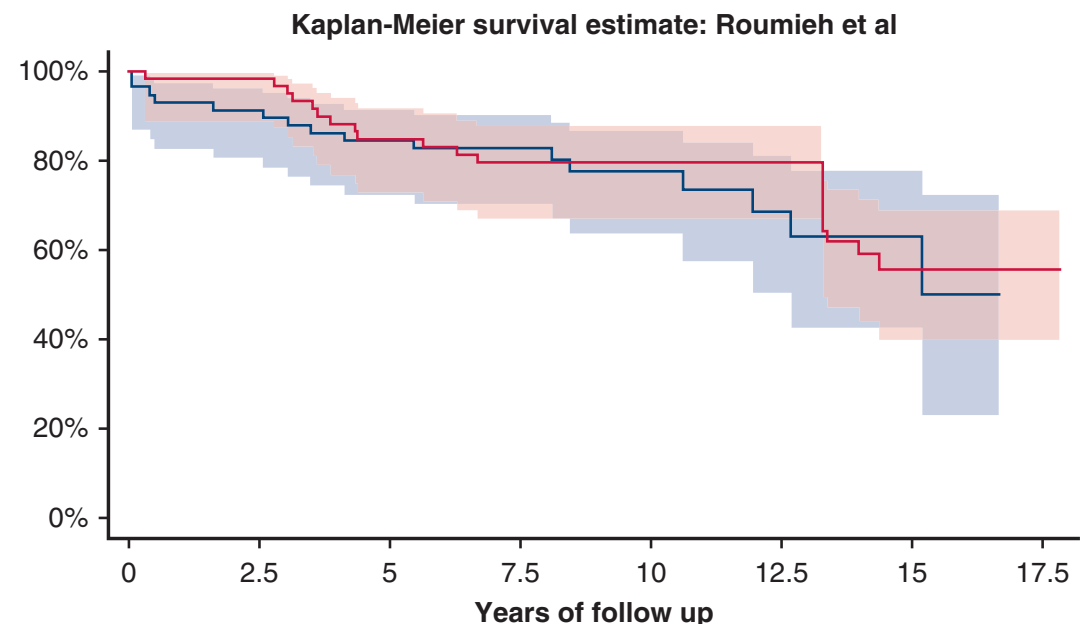

Number at risk

Biological 60

Mechanical 60

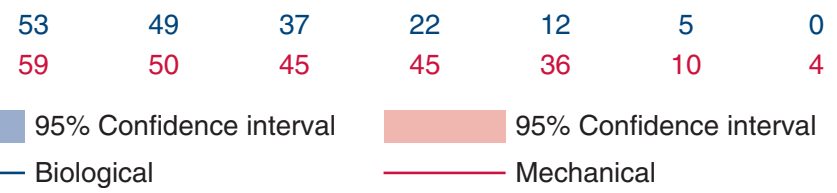

FIGURE E2. Reconstructed Kaplan-Meier survival curves of Roumieh and colleagues. ${ }^{18}$ 


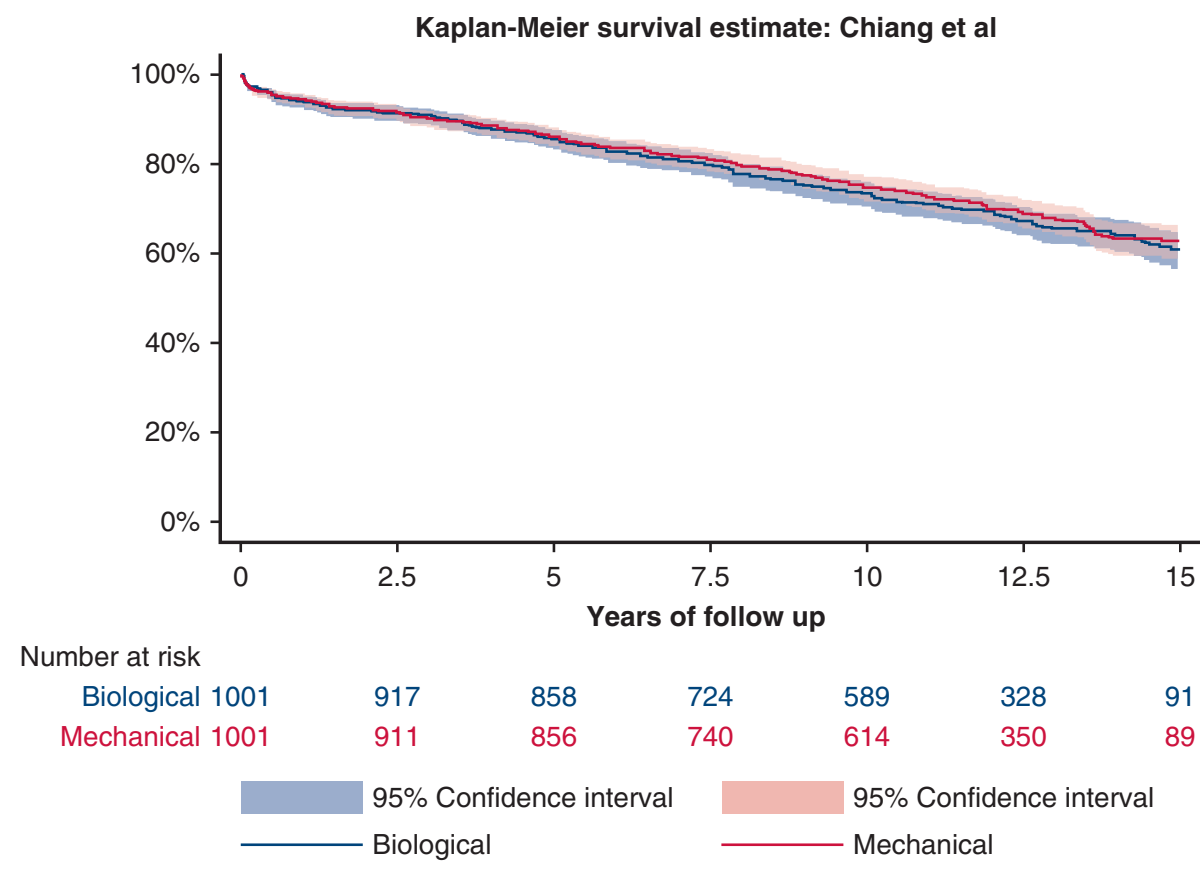

FIGURE E3. Reconstructed Kaplan-Meier survival curves of Chiang and colleagues. ${ }^{3}$

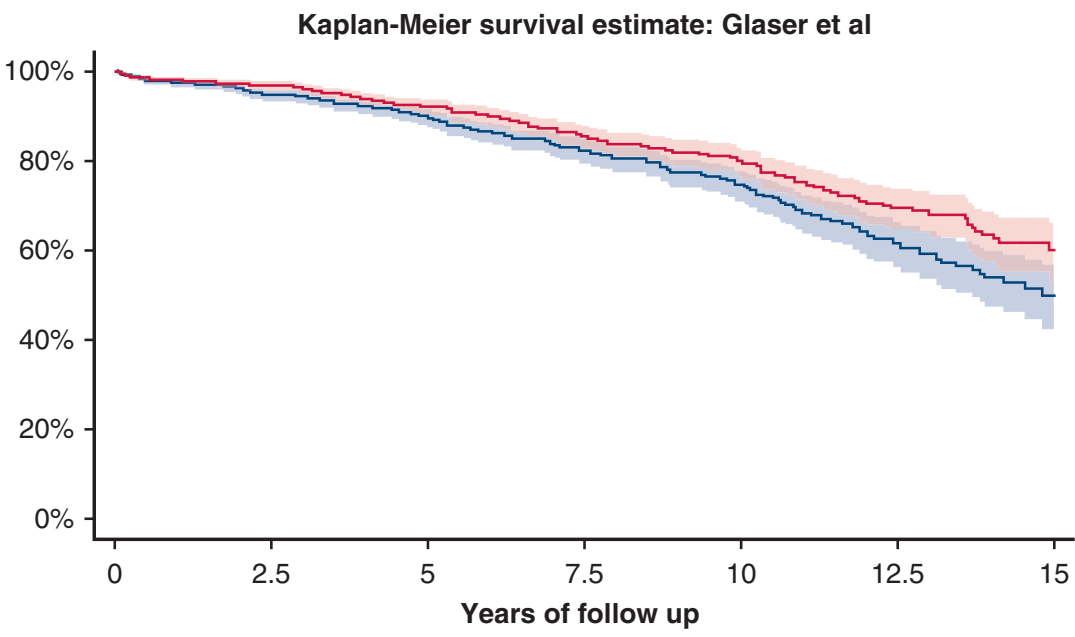

Number at risk

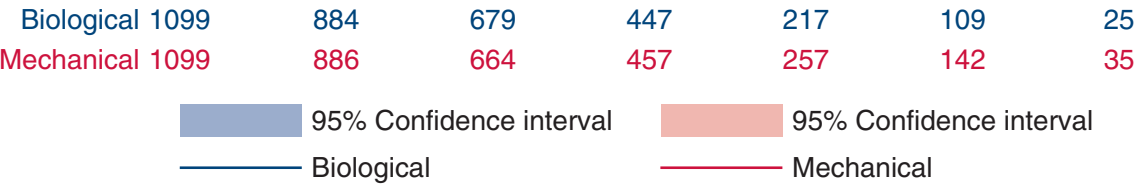

FIGURE E4. Reconstructed Kaplan-Meier survival curves of Glaser and colleagues. ${ }^{5}$ 


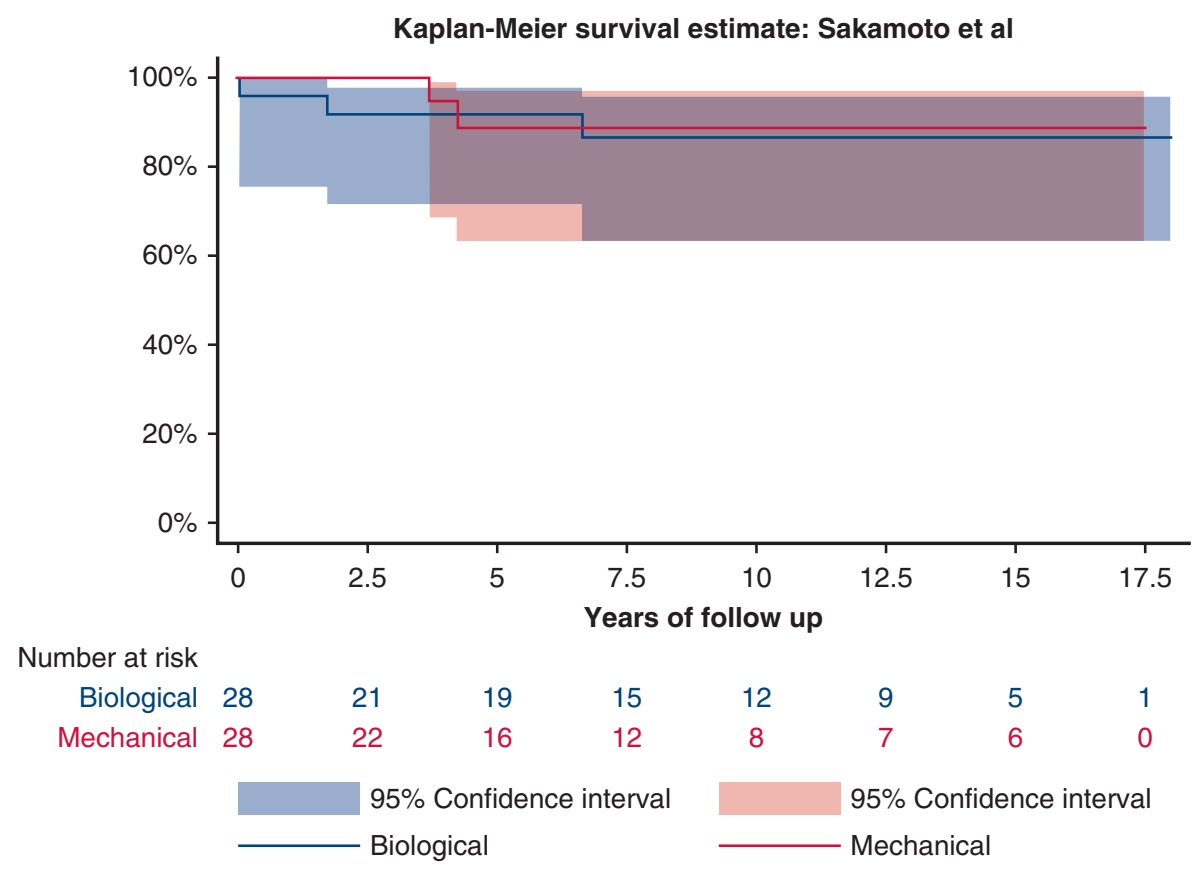

FIGURE E5. Reconstructed Kaplan-Meier survival curves of Sakamoto and colleagues. ${ }^{19}$

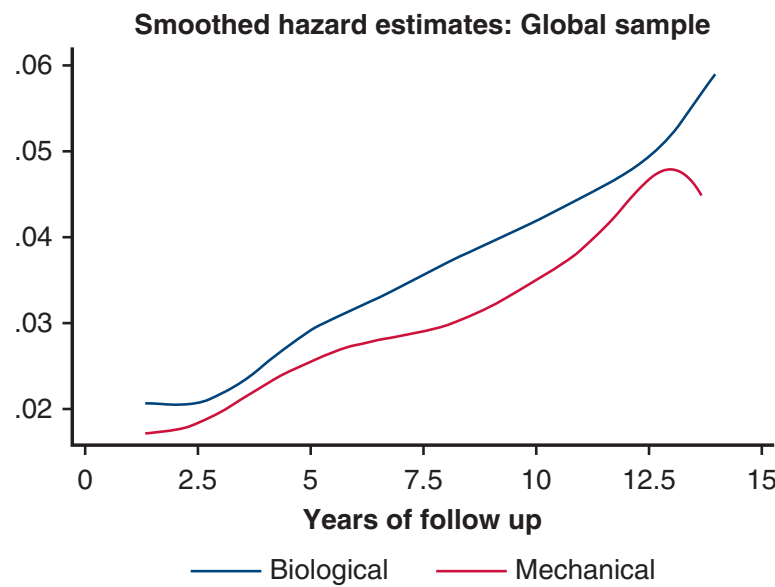

FIGURE E6. Smoothed hazard function of the global sample. 


\begin{tabular}{|c|c|c|c|c|c|}
\hline Reference & $\begin{array}{l}\text { Study } \\
\text { design }\end{array}$ & $\longleftarrow$ Favors mechanical & Favors biological & ES (95\% Cl) & $\begin{array}{c}\% \\
\text { Weight }\end{array}$ \\
\hline Stassano et al ${ }^{17}$ & $\mathrm{RCT}$ & & - & $0.79(0.52-1.21)$ & 7.17 \\
\hline Roumieh et $\mathrm{al}^{18}$ & PSM & & & $0.88(0.45-1.72)$ & 2.87 \\
\hline Chiang et $\mathrm{al}^{3}$ & PSM & & & $0.96(0.83-1.11)$ & 59.27 \\
\hline Glaser et al ${ }^{5}$ & PSM & & & $0.75(0.61-0.92)$ & 30.29 \\
\hline Sakamoto et al ${ }^{19}$ & PSM & & & $0.73(0.12-4.42)$ & 0.39 \\
\hline \multicolumn{3}{|c|}{ Overall $\left(I^{2}=0.0 \%, P=.412\right)$} & & $0.88(0.78-0.98)$ & 100.00 \\
\hline
\end{tabular}

FIGURE E7. Forest plot for late survival with aggregated data.

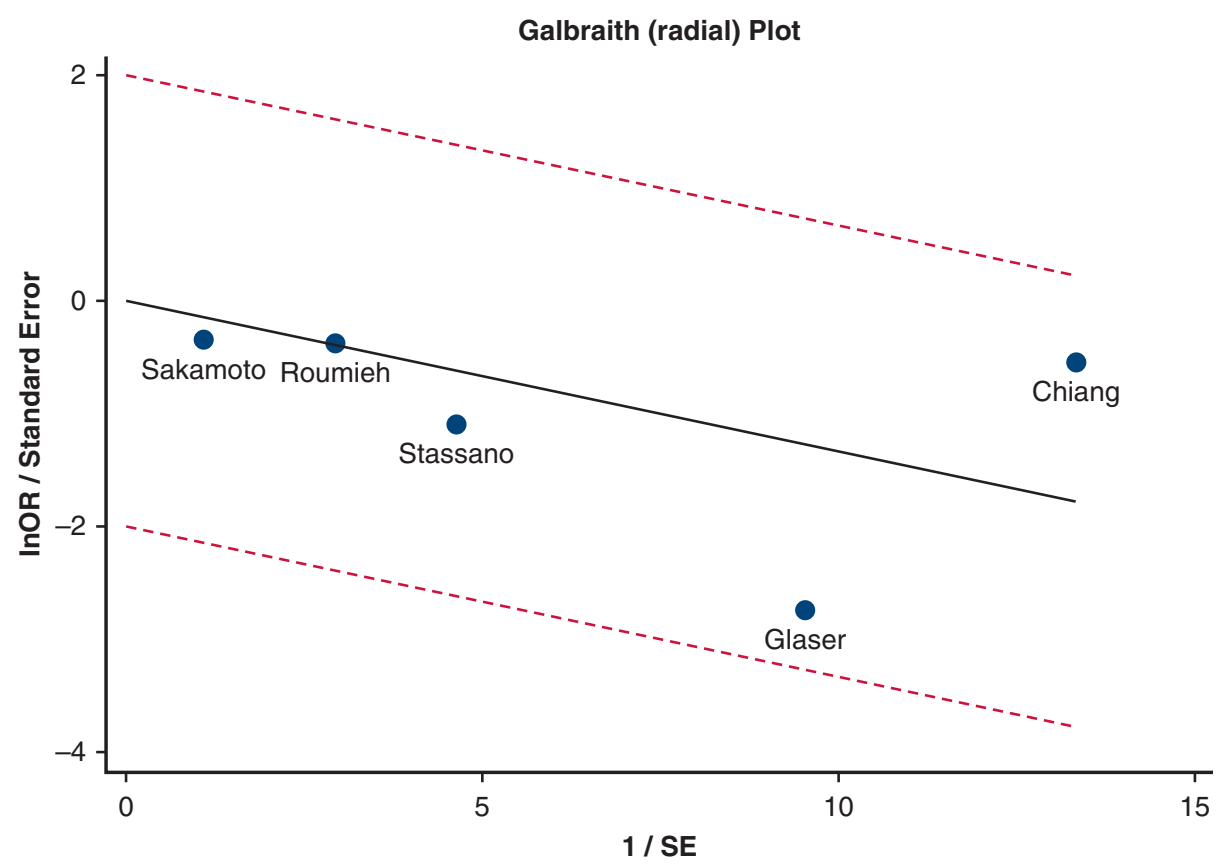

FIGURE E8. Galbraith plot to assess heterogeneity. Studies between the red lines indicate consistency. 


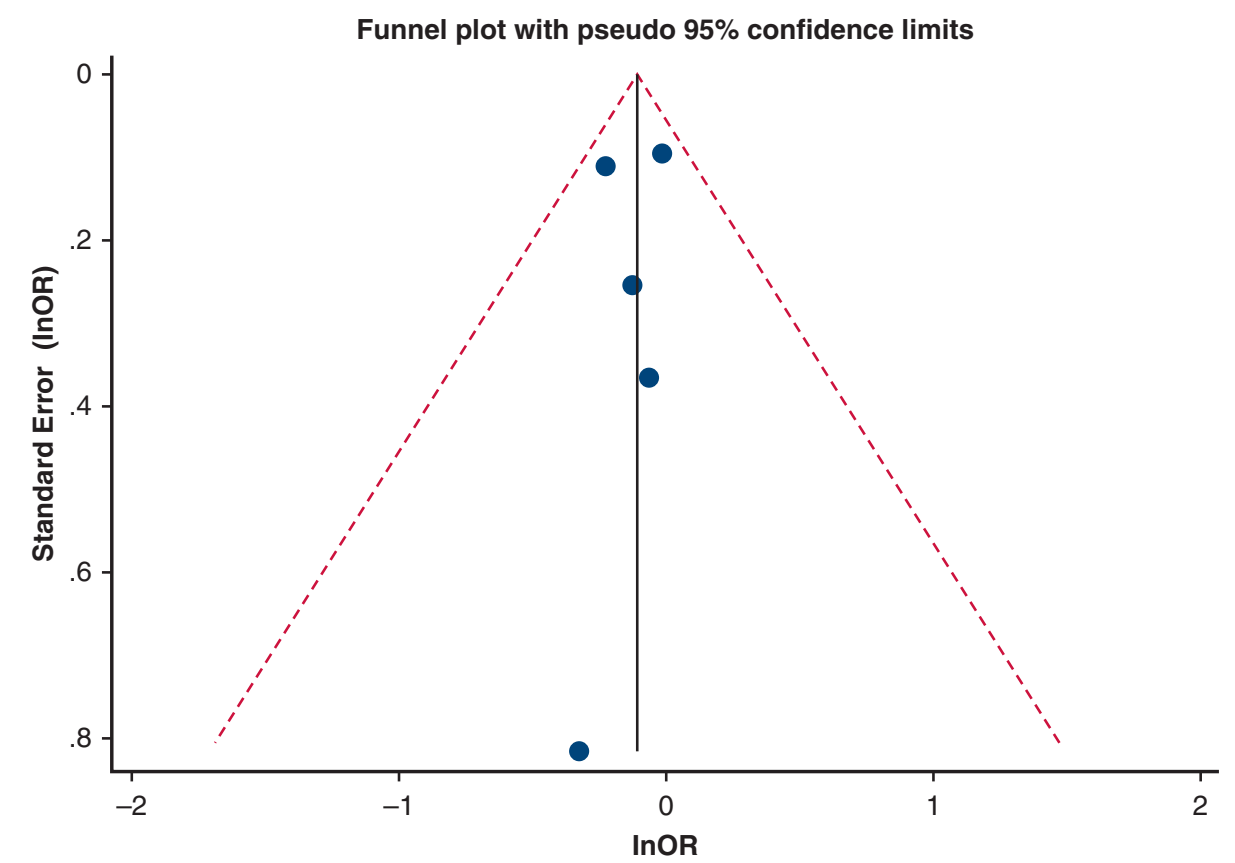

FIGURE E9. Funnel plot to assess publication bias. Studies between the red lines indicate no publication bias.

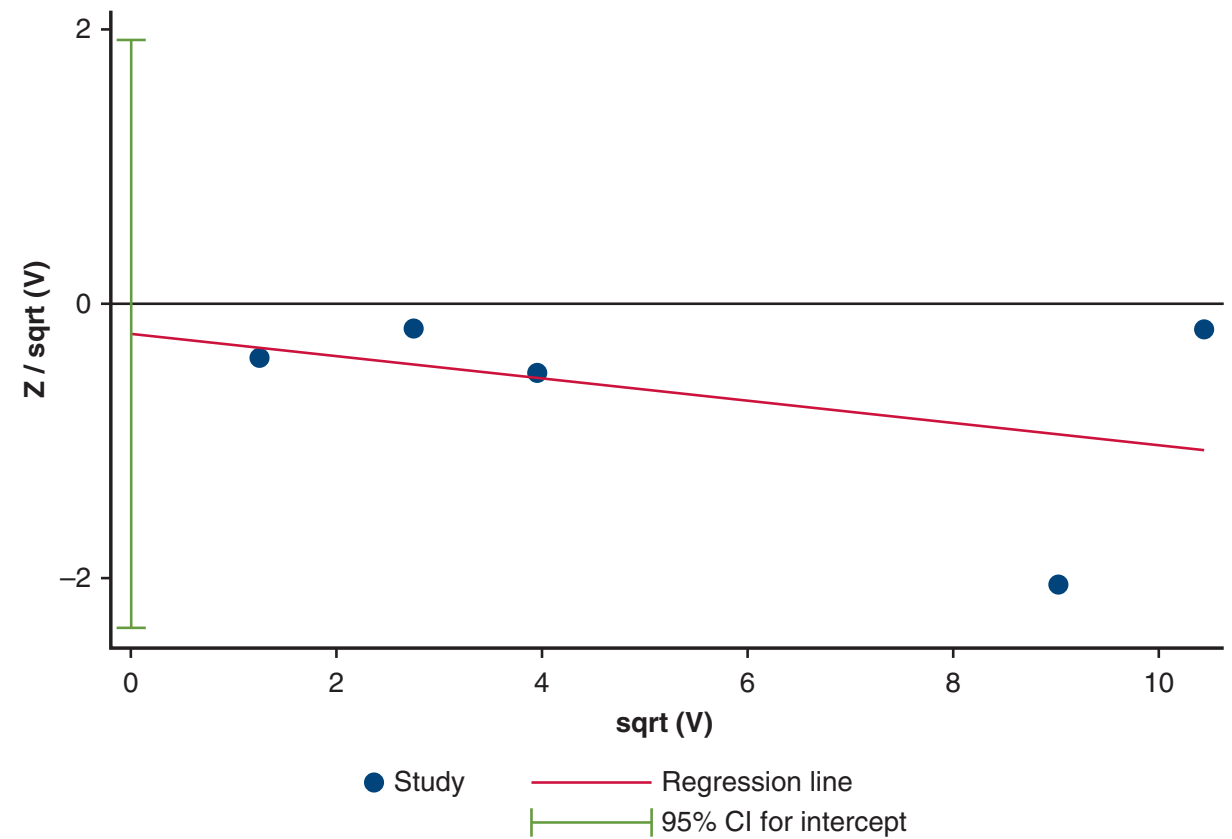

FIGURE E10. Harbord plot to assess publication bias. Studies between the confidence interval indicate no publication bias. 


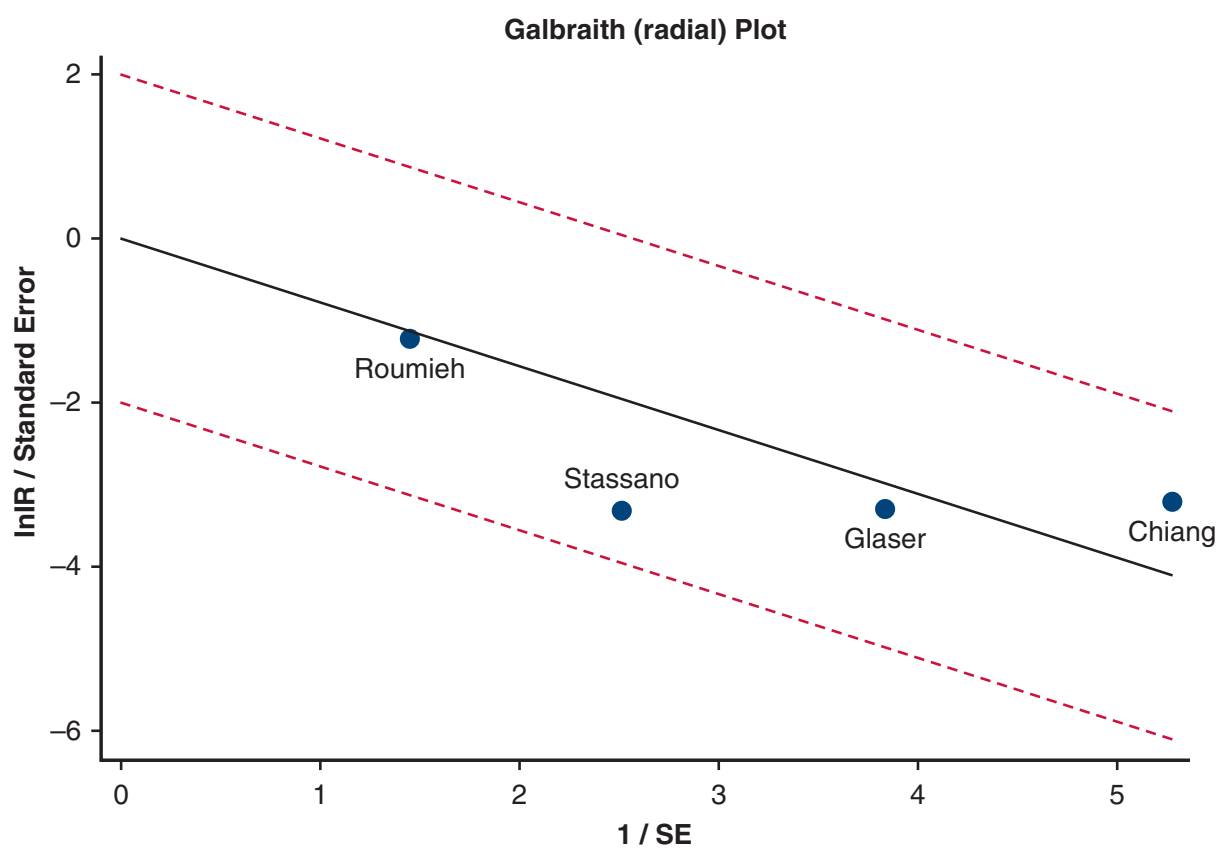

FIGURE E11. Galbraith plot to assess heterogeneity. Studies between the red lines indicate consistency.

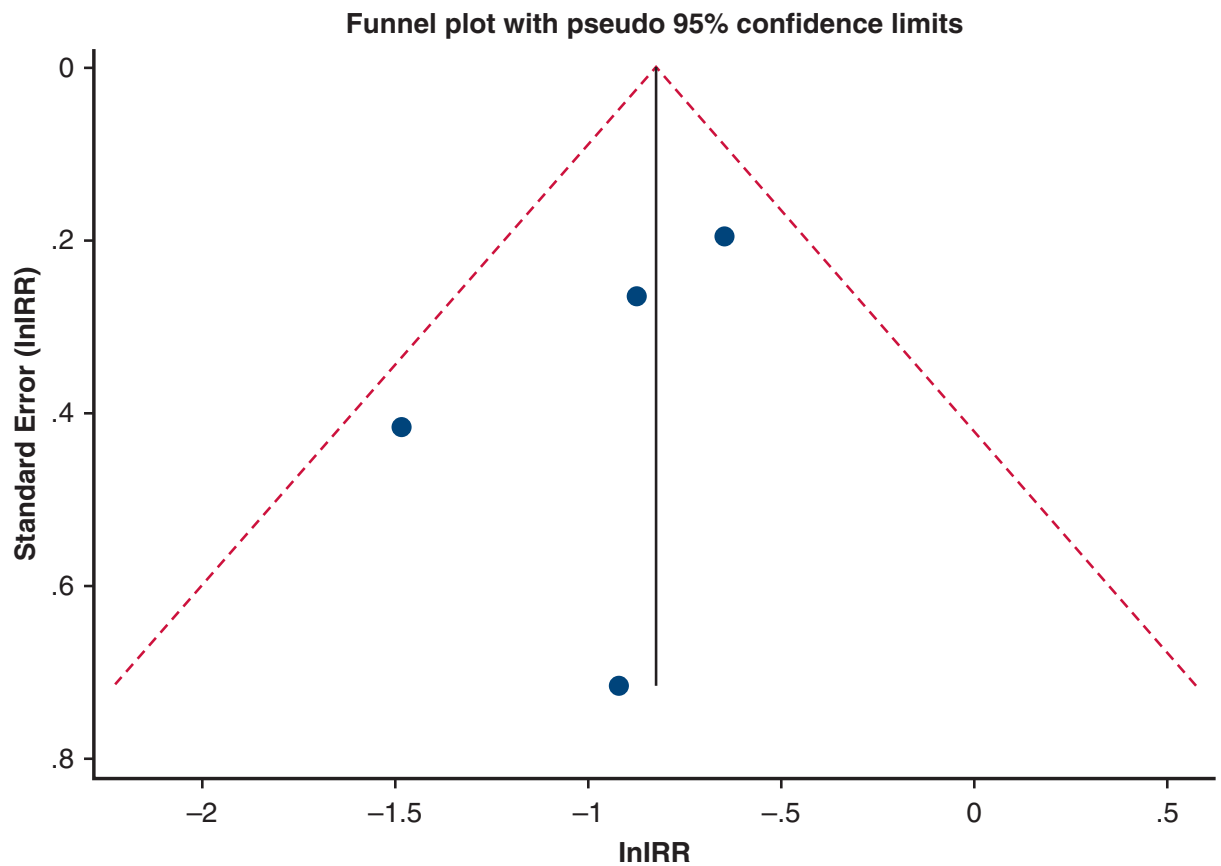

FIGURE E12. Funnel plot to assess publication bias. Studies between the red lines indicate no publication bias. 


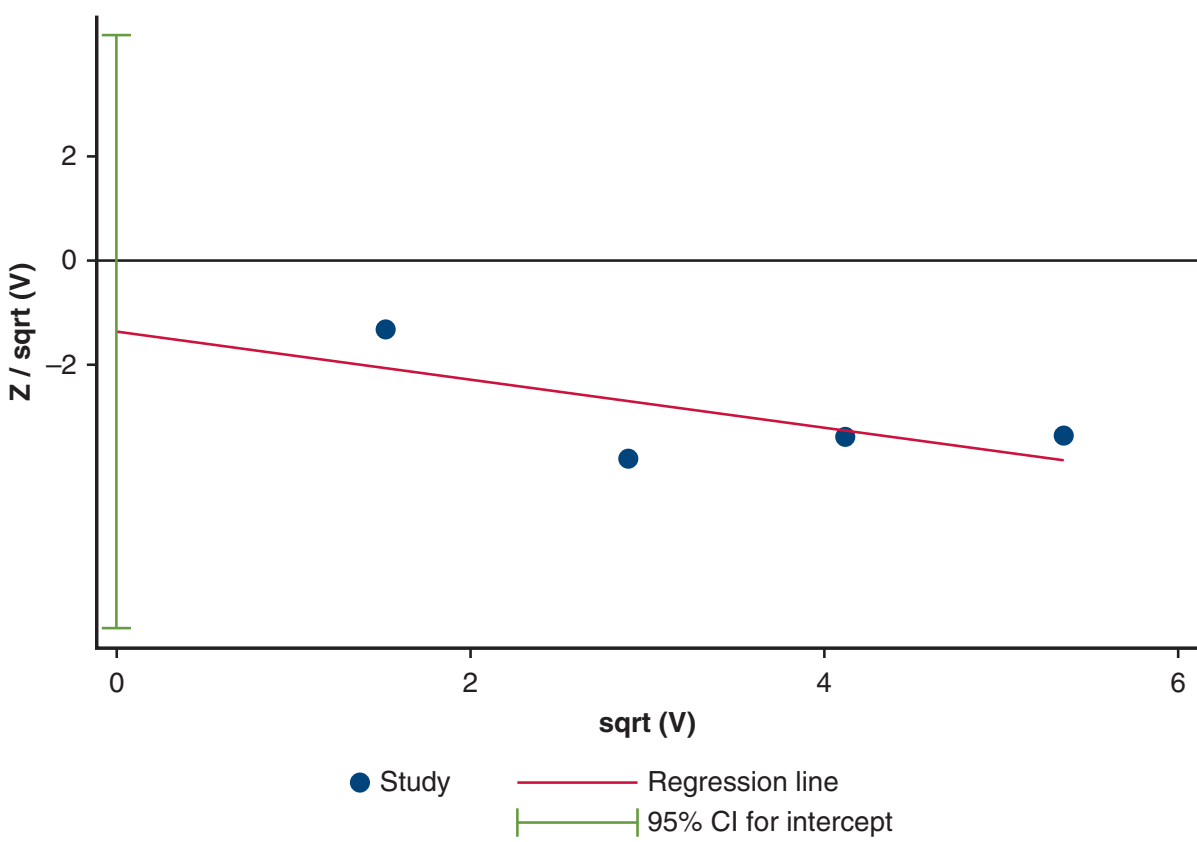

FIGURE E13. Harbord plot to assess publication bias. Studies between the confidence interval indicate no publication bias.

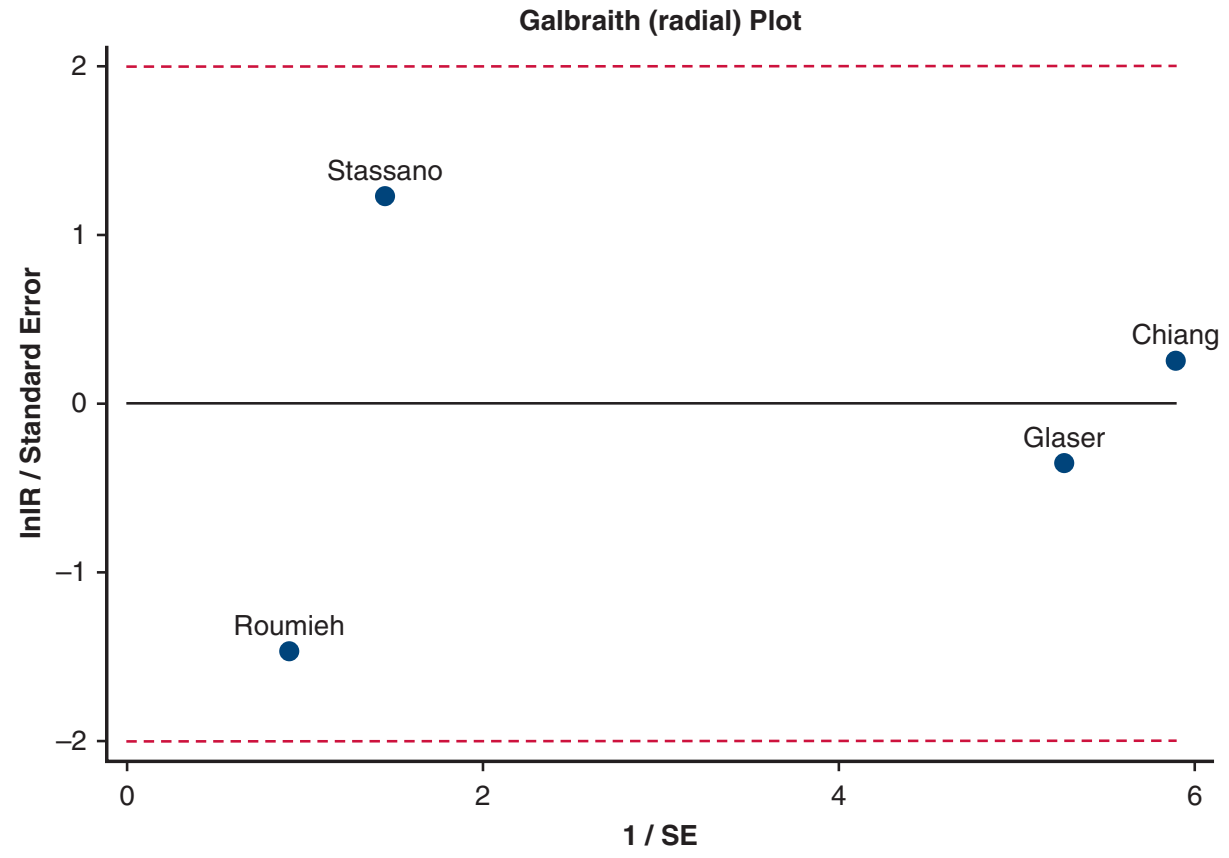

FIGURE E14. Galbraith plot to assess heterogeneity. Studies between the red lines indicate consistency. 


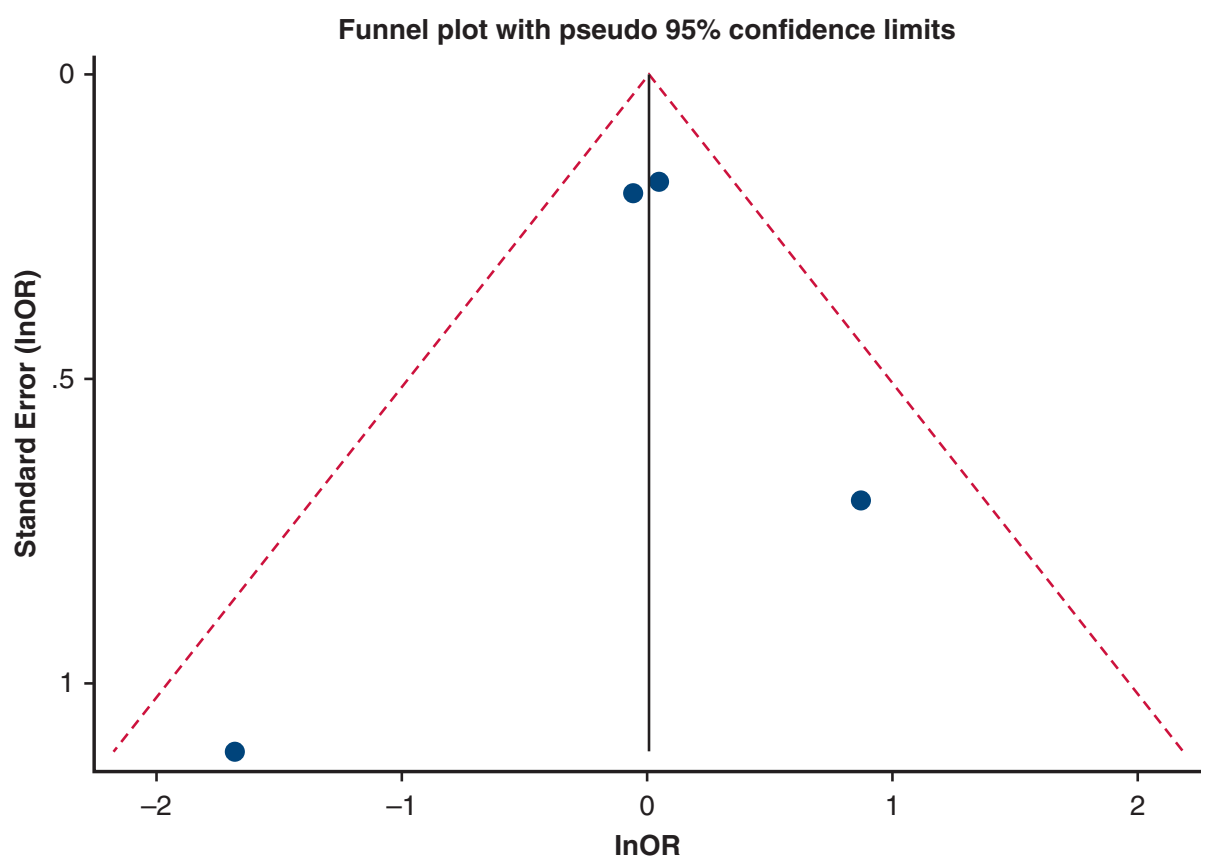

FIGURE E15. Funnel plot to assess publication bias. Studies between the red lines indicate no publication bias.

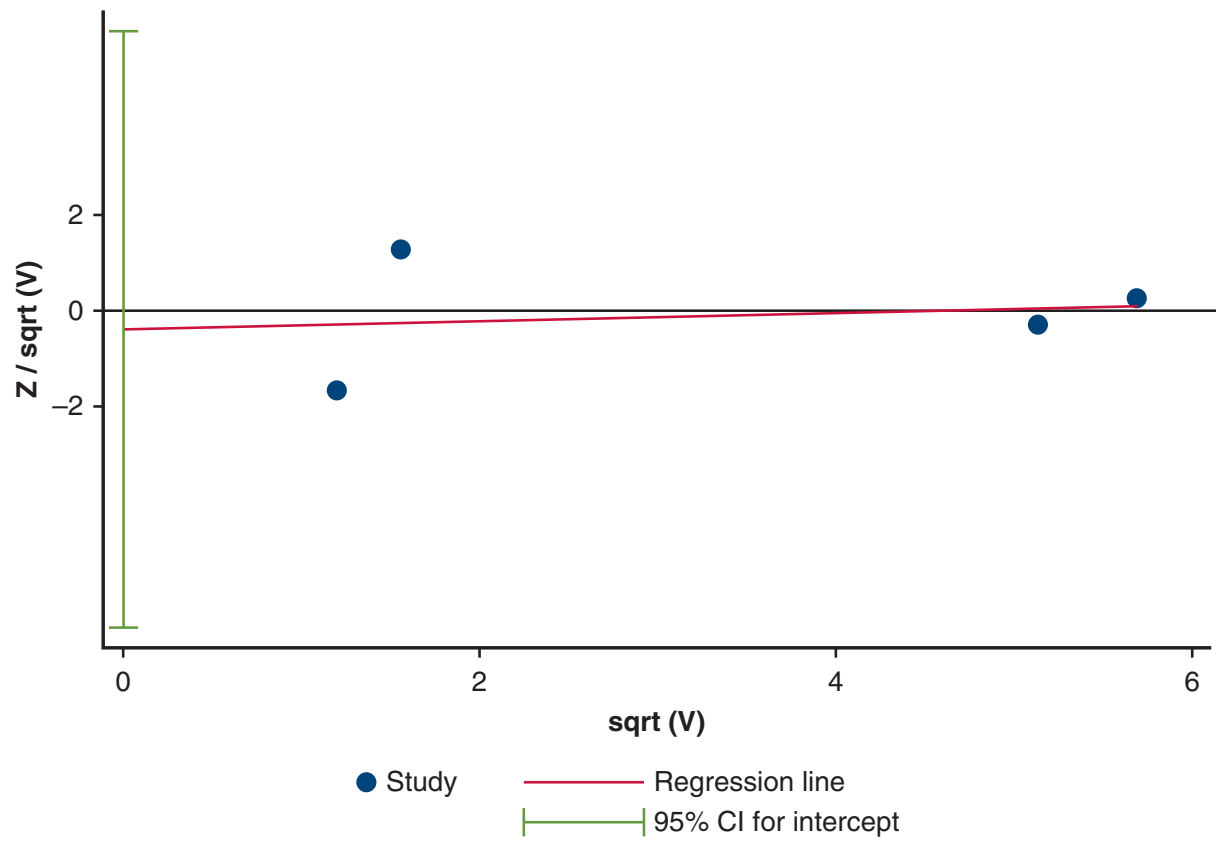

FIGURE E16. Harbord plot to assess publication bias. Studies between the confidence interval indicate no publication bias. $C I$, Confidence interval. 


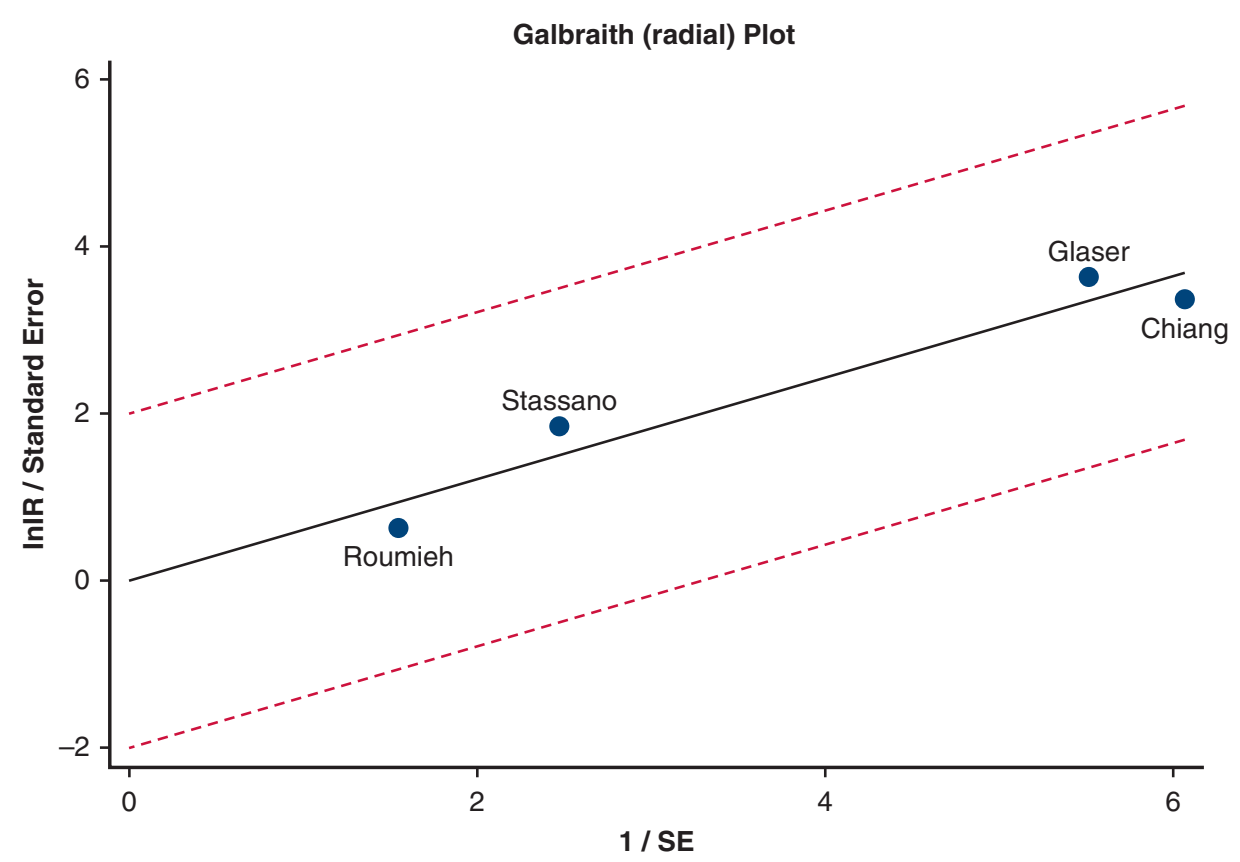

FIGURE E17. Galbraith plot to assess heterogeneity. Studies between the red lines indicate consistency.

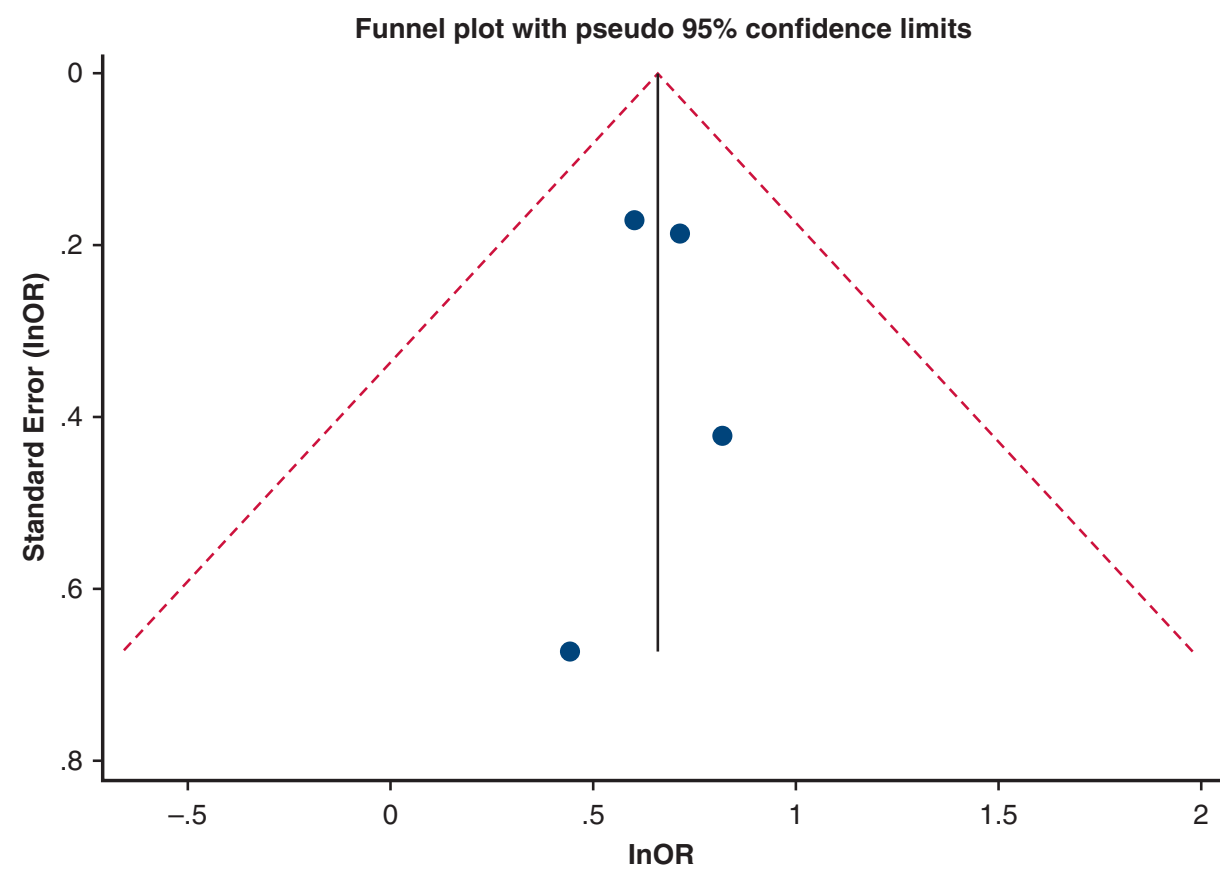

FIGURE E18. Funnel plot to assess publication bias. Studies between the red lines indicate no publication bias. 


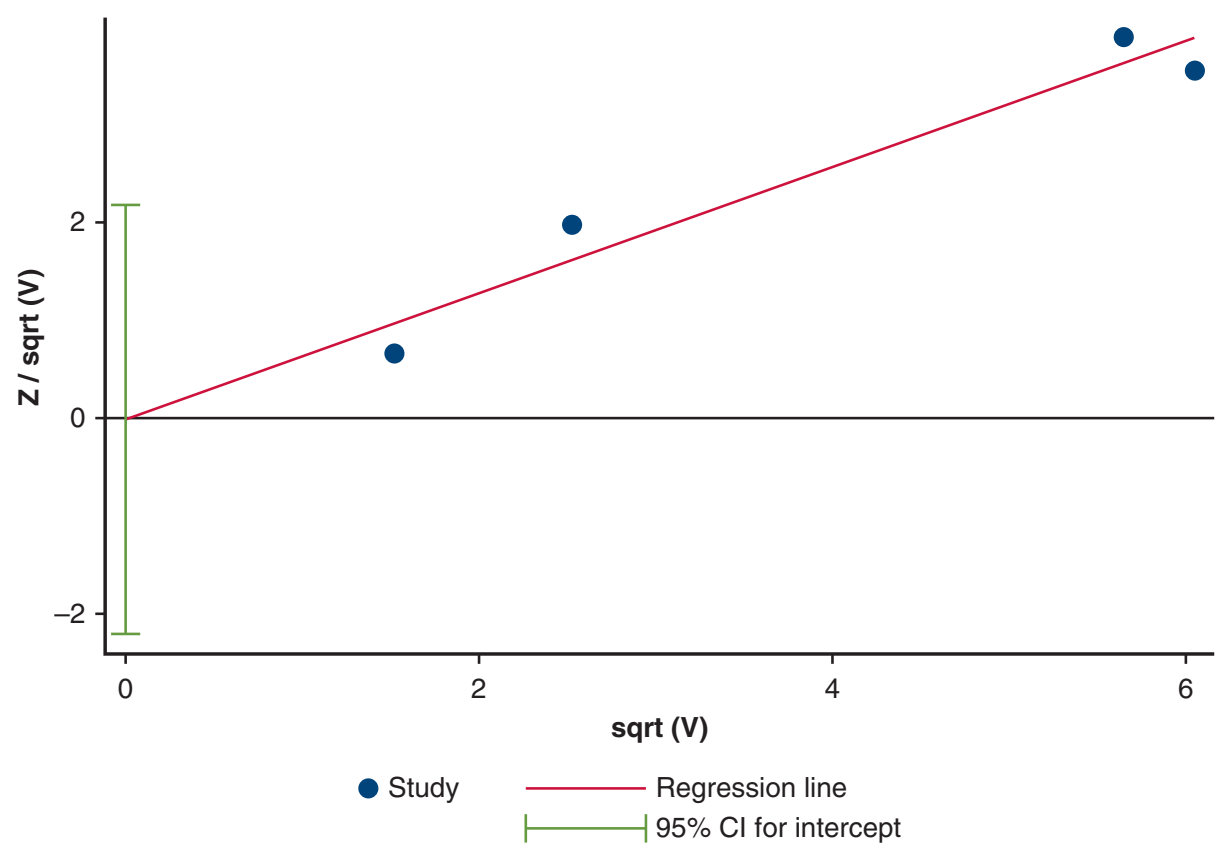

FIGURE E19. Harbord plot to assess publication bias. Studies between the confidence interval indicate no publication bias. $C I$, Confidence interval. 
TABLE E1. Patient characteristics in included studies according to the implantation of a mechanical or biological aortic prosthesis

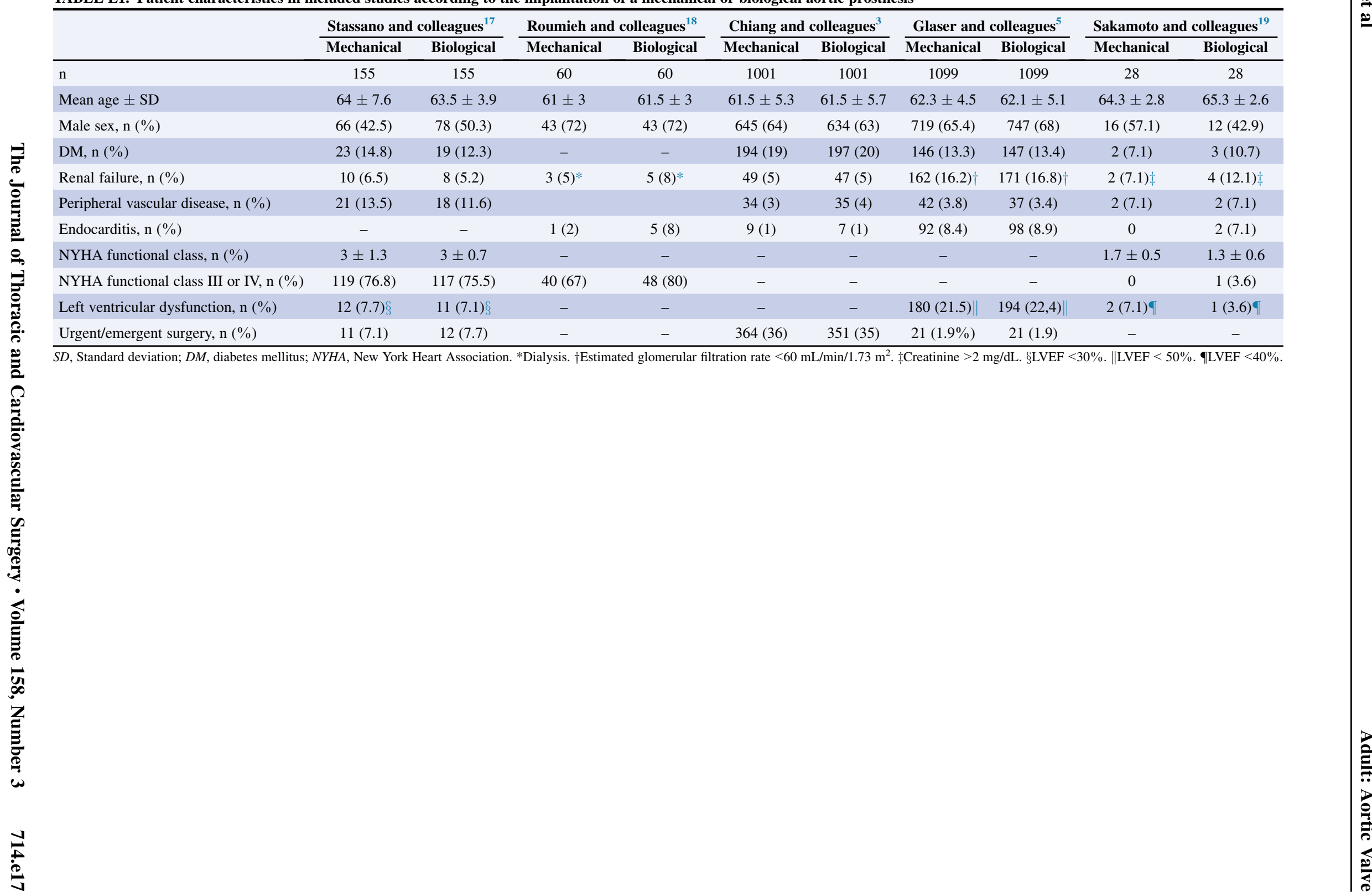


TABLE E2. Influential and sensitivity analysis

\begin{tabular}{|c|c|c|c|c|c|c|c|}
\hline \multirow[b]{3}{*}{ Reference } & \multicolumn{6}{|c|}{ IoV fixed effect model estimation if the study is deleted } & \multirow{3}{*}{$\frac{\text { Relative weights }}{\text { IoV FEM, \% }}$} \\
\hline & \multicolumn{3}{|c|}{$95 \%$ Confidence interval } & \multirow[b]{2}{*}{ HRw change } & \multicolumn{2}{|c|}{ Heterogeneity } & \\
\hline & HRw & Lower & Upper & & $I^{2}$ & $P$ value & \\
\hline Stassano and colleagues ${ }^{17}$ & 0.88 & 0.78 & 0.99 & $0.8 \%$ & $19.2 . \%$ & .29 & 7.2 \\
\hline Roumieh and colleagues ${ }^{18}$ & 0.88 & 0.78 & 0.98 & $-0.0 \%$ & $24.2 \%$ & .27 & 2.9 \\
\hline Chiang and colleagues ${ }^{3}$ & 0.77 & 0.64 & 0.91 & $-12.6 \%$ & $0.0 \%$ & .97 & 59.3 \\
\hline Glaser and colleagues $^{5}$ & 0.94 & 0.82 & 1.07 & $6.9 \%$ & $0.0 \%$ & .84 & 30.3 \\
\hline Sakamoto and colleagues ${ }^{19}$ & 0.88 & 0.78 & 0.98 & $0.1 \%$ & $23.4 \%$ & .27 & 0.4 \\
\hline None & 0.88 & 0.78 & 0.98 & $0.0 \%$ & $0 \%$ & .41 & $100 \%$ \\
\hline
\end{tabular}

IoV, Inverse of Variance; $H R w$, Hazard Ratio weighted; FEM, Fixed Effect Method.

TABLE E3. Reported causes of death for each individual study

\begin{tabular}{|c|c|c|}
\hline \multirow[b]{2}{*}{ Reference } & \multicolumn{2}{|c|}{ Cause of death } \\
\hline & Biological & Mechanical \\
\hline \multicolumn{3}{|l|}{ Stassano and colleagues ${ }^{17}$} \\
\hline \multirow[t]{3}{*}{ Early death } & Perioperative myocardial infarction: $2(1.3 \%)$ & Perioperative myocardial infarction: $1(0.6 \%)$ \\
\hline & Low cardiac output syndrome: $3(1.9 \%)$ & Low cardiac output syndrome: $2(1.3 \%)$ \\
\hline & Pulmonary complications: $1(0.6 \%)$ & Cerebrovascular accident: $1(0.6 \%)$ \\
\hline \multirow[t]{2}{*}{ Late death } & Cardiac-related mortality: $32(21.7 \%)$ & Cardiac-related mortality: $25(16.7 \%)$ \\
\hline & Valvular-related mortality:12 (8.1\%) & Valvular-related mortality: $10(6.7 \%)$ \\
\hline \multicolumn{3}{|l|}{ Roumieh and colleagues ${ }^{18}$} \\
\hline \multirow[t]{2}{*}{ Early death } & Sepsis: $1(1.6 \%)$ & There was no hospital mortality \\
\hline & Unexplained asystolic arrest: $1(1.6 \%)$ & \\
\hline Late death & Cardiac-related mortality: $7(12 \%)$ & Cardiac-related mortality: $12(20 \%)$ \\
\hline Chiang and colleagues ${ }^{3}$ & Not reported & Not reported \\
\hline Glaser and colleagues $^{5}$ & Cardiovascular mortality: 48 (5.1\%) & Cardiovascular mortality: $49(5.2 \%)$ \\
\hline Sakamoto and colleagues ${ }^{19}$ & Not reported & Not reported \\
\hline
\end{tabular}

